\title{
Temporal and spatial distribution of transparent exopolymer particles off the northern coast of Baja California, Mexico
}

\section{Distribución temporal y espacial de partículas de exopolímeros transparentes frente a la costa norte de Baja California, México}

\author{
Cristian Hakspiel-Segura' ${ }^{1}$, Ramón Cajal-Medrano², Helmut Maske-Rubach², \\ Josué Villegas-Mendoza ${ }^{3}$ \\ 1 Instituto de Investigaciones Oceanológicas, Universidad Autónoma de Baja California, Carretera \\ Transpeninsular Ensenada-Tijuana, no. 3917, Fraccionamiento Playitas, CP 22860, Ensenada, Baja \\ California, México. \\ 2 Department of Biological Oceanography, Centro de Investigación Científica y de Educación Superior de \\ Ensenada (CICESE), Carretera Ensenada-Tijuana, no. 3918, Zona Playitas, CP 22860, Ensenada, Baja \\ California, México. \\ 3 Facultad de Ciencias Marinas, Universidad Autónoma de Baja California, Carretera Transpeninsular \\ Ensenada-Tijuana, no. 3917, Fraccionamiento Playitas, CP 22860, Ensenada, Baja California, México.
}

* Corresponding author. E-mail: chakspiel@uabc.edu.mx

\begin{abstract}
Transparent exopolymer particles (TEP) have been reported as a significant fraction of organic microgels in different oceans. No TEP data have been published for the California Current region off Baja California that indicate the potential contribution of this reservoir to the carbon budget. We measured TEP in seawater samples, using the spectrophotometric method with alcian blue stain, and additional environmental and biological variables during 3 seasons at coastal stations between $\sim 1.4$ and 12.0 mi offshore, near $31^{\circ} \mathrm{N}$. Concentrations of TEP obtained with $0.45 \mu \mathrm{m}$ pore size filters showed spatial and temporal distributions with a tendency to increase from offshore to nearshore and

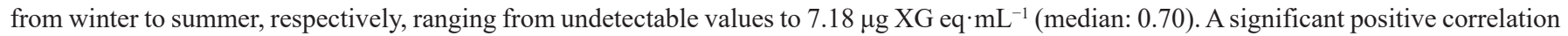
was observed between the concentration of TEP and bacterioplankton abundance $(P<0.05)$, and between total organic carbon and bacterioplankton abundance $(P<0.05)$. Transparent exopolymer particles also presented a negative correlation with community respiration $(P<0.05)$, suggesting that TEP provided a physical substrate for settlement of prokaryotic microorganisms but probably did not supply labile carbon. We compared the concentration of alcian blue stainable particles retained by the standard $0.45 \mu \mathrm{m}$ pore size with the concentration obtained with $0.22 \mu \mathrm{m}$ filters; the latter showed 1.7 to 64.0 fold (median: 4.1) higher TEP concentrations. This strong dependence of TEP concentration on pore size makes it difficult to define the quantitative contribution of TEP and their precursors to particulate organic matter and their role in the carbon cycle. Further studies on TEP in the Mexican portion of the California Current must corroborate the observed spatial and seasonal trends, and estimate a TEP-to-carbon conversion factor that provides a better approximation to its contribution to the regional carbon budget.
\end{abstract}

Key words: transparent exopolymer particles, bacterioplankton abundance, community respiration, hydrography, California Current.

RESUMEN. Las partículas de exopolímeros transparentes (PET) constituyen una fracción significativa de los microgeles orgánicos en diferentes océanos. Para la corriente de California frente a Baja California, aún no existen datos de PET publicados que indiquen la contribución potencial de esta reserva al presupuesto de carbono. Se midieron las PET en muestras de agua de mar, usando el método espectrofotométrico con tinción de azul alcián, así como variables ambientales y biológicas en estaciones costeras cercanas a $31^{\circ} \mathrm{N}$, entre $\sim 1.4$ y 12.0 mi de la costa, durante 3 temporadas. Las concentraciones de PET obtenidas con membranas de tamaño de poro de $0.45 \mu$ m presentaron distribución espacial y distribución temporal con una tendencia a incrementar del océano a la costa, y de invierno a verano, respectivamente, y fluctuaron desde niveles

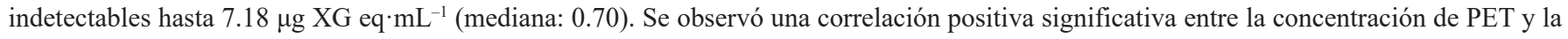
abundancia de bacterioplancton $(P<0.05)$, y entre el carbono orgánico total y el bacterioplancton $(P<0.05)$. Las PET presentaron una correlación negativa con la respiración comunitaria $(P<0.05)$, lo cual sugiere que la materia orgánica de las PET funciona como sustrato físico para el asentamiento de microorganismos procarióticos y no como suplemento de carbono lábil. Se comparó la concentración de partículas teñidas con azul alcián retenidas por el tamaño de poro operativo de $0.45 \mu \mathrm{m}$ con la obtenida con filtros de $0.22 \mu \mathrm{m}$, esta última entre 1.7 y 64.0 veces (mediana: 4.1) mayor. Esta fuerte dependencia de la concentración de PET al tamaño de poro dificulta definir la contribución cuantitativa de PET y sus precursores a la materia orgánica particulada, y su papel en el ciclo del carbono. Otros estudios sobre las PET en la parte mexicana de la corriente de California deben corroborar las tendencias espaciotemporales que fueron observadas, así como ponderar un factor de conversión a carbono que provea una mejor aproximación de su contribución al presupuesto de carbono.

Palabras clave: partículas de exopolímeros transparentes, abundancia de bacterioplancton, respiración comunitaria, hidrografía, corriente de California. 


\section{INTRODUCTION}

Transparent exopolymer particles (TEP) constitute a key component of nonliving particulate organic matter in seawater (Kaltenböck and Herndl 1992). Transparent exopolymer particles, also defined as a self-assemblage microgels $(>0.4$ $\mu \mathrm{m})$ that are stainable with alcian blue, are produced mainly from phytoplankton and bacterioplankton exudates (Bar-Zeev et al. 2012). These particles have highly viscous and sticky properties that allow them to bind to each other and coagulate in a wide range of sizes, becoming part of the size continuum from dissolved to large organic aggregates (Alldredge et al. 1993, Ding et al. 2009, Verdugo 2012). Transparent exopolymer particles have been implicated in the sequestering of trace metals, considered as hot spots of intense microbial activity, and held responsible for the formation of the matrix that embeds sinking particles (Passow 2002). In this way, the contribution of TEP to the cycles of carbon and other elements acquires great relevance due to their interaction with ocean physics and microbial physiology, which may define the amount of compounds that are exported to the ocean floor or are remineralized in the water column.

The biological and environmental factors that control the assembly of TEP in the marine environment are not well known. Marine dissolved organic precursors may coagulate under conditions of strong turbulence and pronounced gradients of salinity (Stoderegger and Herndl 1999, Engel 2000, Surge and Lohmann 2002). Other factors that have been shown to influence the formation or disintegration of TEP are $\mathrm{pH}$, cation availability (such as $\mathrm{Ca}^{2+}$ and $\mathrm{Mg}^{2+}$ ), and temperature (Chin et al. 1998, Chen et al. 2015, Baltar et al. 2016). Although little is known about the mechanical architecture and chemical composition of TEP, these particles are abundant in carbon-rich acidic polysaccharides that contain some reactive groups (carboxyl and half-ester sulphate) (Passow 2002). These organic molecules may form visible complexes and also be easily quantified by spectrophotometry through staining with alcian blue after filtration of water samples through $0.45 \mu \mathrm{m}$ pore size filters (Passow and Alldredge 1995). The use of these filters has allowed the creation of a worldwide data stock in the last decades. The smaller pores are known to increase the collection of TEP but this has not been investigated in detail (Villacorte et al. 2015).

There are no previous reports about TEP concentrations or their possible contribution to the carbon budget in Pacific waters off western Mexico. Here we report TEP concentrations under different oceanographic conditions in some locations off the northern coast of Baja California (Mexico). This area has a marked environmental gradient perpendicular to the coast, which is seasonally influenced by upwelling processes associated with the California Current System. We expected to find a triggered increase of exudates derived from primary producers during the upwelling season (e.g., phytoplankton and macroalgae) and that these exudates then coagulate as TEP (Engel 2000, Chen and Thornton 2015). Moreover, we

\section{INTRODUCCIÓN}

Las partículas de exopolímeros transparentes (PET) constituyen un componente clave de la materia orgánica particulada inerte en el agua de mar (Kaltenböck y Herndl 1992). Las PET, que se definen como microgeles autoensamblados $(>0.4 \mu \mathrm{m})$ que son teñibles con azul alcián, son producidas principalmente de exudados del fitoplancton y el bacterioplancton (Bar-Zeev et al. 2012). Estas partículas tienen alta viscosidad y propiedades pegajosas que permiten la unión entre ellas y la coagulación en una amplia gama de tamaños, convirtiéndose en parte del continuo de tamaños desde sustancias orgánicas disueltas hasta grandes agregados (Alldredge et al. 1993, Ding et al. 2009, Verdugo 2012). Las PET han sido relacionadas con el secuestro de metales traza, así como consideradas como puntos focales de intensa actividad microbiana y responsables de la formación de la matriz que incorpora a partículas en hundimiento (Passow 2002). Por lo tanto, la contribución de las PET a los ciclos de carbono y otros elementos adquiere gran relevancia debido a que su interacción con la física oceánica y la fisiología microbiana puede definir la cantidad de compuestos que se exportan al fondo oceánico o son remineralizados en la columna de agua.

Los factores biológicos y ambientales que controlan el ensamblaje de las PET en el medio marino no son bien conocidos. Los precursores orgánicos disueltos en el mar pueden coagular en condiciones de fuerte turbulencia y pronunciados gradientes de salinidad (Stoderegger y Herndl 1999, Engel 2000, Surge y Lohmann 2002). Otros factores que influyen en la formación o desintegración de las PET son el pH, la disponibilidad de cationes (como $\mathrm{Ca}^{2+}$ y $\mathrm{Mg}^{2+}$ ) y la temperatura (Chin et al. 1998, Chen et al. 2015, Baltar et al. 2016). Aunque se sabe poco sobre su arquitectura mecánica y su composición química, las PET son abundantes en polisacáridos ácidos ricos en carbono que contienen algunos grupos reactivos (carboxilo y sulfato de semiéster) (Passow 2002). Estas moléculas orgánicas pueden formar complejos visibles y también pueden cuantificarse fácilmente por un método espectrofotométrico mediante la tinción con azul alcián después de la filtración de muestras de agua a través de poros de $0.45 \mu \mathrm{m}$ (Passow y Alldredge 1995). El uso de estos filtros ha permitido generar un acervo global de información en las últimas décadas. Se sabe que los poros más pequeños aumentan la retención de PET, pero esto no se ha investigado a detalle (Villacorte et al. 2015).

Para las aguas del Pacífico frente a México, no existen antecedentes de las concentraciones de PET, ni de su posible contribución al presupuesto de carbono. Aquí, presentamos concentraciones de PET bajo diferentes condiciones oceanográficas en algunas localidades frente a la costa norte de Baja California (México). Esta área tiene un marcado gradiente ambiental perpendicular a la costa, que es influenciado estacionalmente por los procesos de surgencia asociados con el Sistema de la Corriente de California. Se espera que durante el periodo de surgencia se desencadene un aumento 
expected TEP to provide organic nutrition and/or hotspots for microbial activity and, consequently, control a significant fraction of the vertical fluxes of organic material (AzetsuScott and Niven 2005, Bar-Zeev and Rahav 2015, Bochdansky et al. 2016). We also evaluated the differences of TEP concentrations obtained with 3 different filter pore sizes to put the results obtained with the traditional $0.45 \mu \mathrm{m}$ pore size in perspective.

\section{MATERIALS AND METHODS}

Sampling was carried out on board the R/V Alpha Helix on the eastern North Pacific, off Baja California, during 3 cruises in 2016: MICMAR-II (AH1602-016), from 11 to 12 February; OMCENS/MICMAR-III (AH1604-019), from 26 to 28 April; and OB2016, from 30 June to 1 July (Jun-Jul) (Table 1). Water samples were collected from 5 depths that were arbitrarily defined according to the maximum depth of the water column, except during the last cruise, when water samples were taken at 8 depths at IMECOCAL station 100.30 and the ANTARES station, and 2 depths at the nearshore Todos Santos Bay station. All water samples were collected using a rosette sampler equipped with 12 standard 8-L Niskin bottles. For hydrographic profiling, the rosette included a Sea-Bird 9 CTD, an SBE 43 oxygen sensor, and a Seapoint fluorometer. The mixed layer depth was estimated from temperature profiles as the distance of the quasi-isothermal layer (Kara 2000), and by considering the time-dependent optimal values of the potential temperature differential $(\Delta \theta)$ that were proposed seasonally for this region by Jeronimo and Gomez-Valdes (2010). Chlorophyll $a$ (Chla) profiles were obtained indirectly from the fluorescence measurements that de los exudados derivados de los productores primarios (e.g., fitoplancton y macroalgas) y que estos exudados posteriormente coagulen como PET (Engel 2000, Chen y Thornton 2015). También se espera que las PET proporcionen nutrición orgánica y/o focos de alta actividad para microorganismos y, en consecuencia, controlen una fracción significativa de los flujos verticales de material orgánico (Azetsu-Scott y Niven 2005, Bar-Zeev y Rahav 2015, Bochdansky et al. 2016). También evaluamos las diferencias entre las concentraciones de PET obtenidas con 3 tamaños de poro de filtro diferentes para poner en perspectiva los resultados obtenidos con el tamaño de poro tradicional de $0.45 \mu \mathrm{m}$.

\section{MATERIALES Y MÉTODOS}

Los muestreos se llevaron a cabo a bordo del B/I. Alpha Helix en el Pacífico nororiental frente a Baja California, México, durante 3 cruceros: MICMAR-II (AH1602-016), del 11 al 12 de febrero; OMCENS/MICMAR-III (AH1604-019), del 26 al 28 de abril; y OB2016, del 30 de junio al 1 de julio de 2016 (junio-julio) (Tabla 1). Se recolectaron muestras de agua a 5 profundidades definidas arbitrariamente de acuerdo con la profundidad máxima de la columna de agua, excepto en el último crucero, en el cual se tomaron las muestras de agua a 8 profundidades en las estaciones IMECOCAL 100.30 y ANTARES, y a 2 profundidades en la estación más costera en la bahía de Todos Santos. Todas las muestras se recolectaron con un muestreador de roseta equipado con 12 botellas estándar tipo Niskin de 8 L. Para los perfiles hidrográficos, la roseta incluyó un CTD Sea-Bird 9, un sensor de oxígeno SBE 43 y un fluorómetro Seapoint. La profundidad de la capa de mezcla se estimó a partir de perfiles de temperatura como

Table 1. Location, environmental features, and collection dates in 2016 for each sampling site.

Tabla 1. Ubicación de los sitios de muestreo, características ambientales y fechas de recolección en 2016.

\begin{tabular}{|c|c|c|c|c|c|}
\hline Location & Coordinates & Environment & Max. depth & $\begin{array}{c}\text { Number of } \\
\text { sampling depths }\end{array}$ & Collection date \\
\hline ENSENADA & $\begin{array}{r}31^{\circ} 40^{\prime} \mathrm{N} \\
116^{\circ} 41^{\prime} \mathrm{W}\end{array}$ & Coastal & $\sim 100$ & 5 & $\begin{array}{l}11 \text { February } \\
27 \text { April } \\
1 \text { July }\end{array}$ \\
\hline MICMAR & $\begin{array}{r}31^{\circ} 35^{\prime} \mathrm{N} \\
116^{\circ} 52^{\prime} \mathrm{W}\end{array}$ & Coastal & $\sim 1,250$ & 5 & $\begin{array}{l}12 \text { February } \\
28 \text { April }\end{array}$ \\
\hline ANTARES & $\begin{array}{r}31^{\circ} 45^{\prime} \mathrm{N} \\
116^{\circ} 57^{\prime} \mathrm{W}\end{array}$ & Oceanic & $\sim 1,100$ & 5 and 8 & $\begin{array}{l}12 \text { February } \\
28 \text { April } \\
1 \text { July }\end{array}$ \\
\hline IMECOCAL 100.30 & $\begin{array}{r}31^{\circ} 41^{\prime} \mathrm{N} \\
116^{\circ} 46^{\prime} \mathrm{W}\end{array}$ & Coastal & $\sim 415$ & 8 & 30 June \\
\hline
\end{tabular}


were calibrated through spectrophotometric determinations on extracts of discrete samples from the water column.

The concentration of TEP was evaluated colorimetrically following the method of Passow and Alldredge (1995). Several aliquots of $20-100 \mathrm{~mL}$ of unfixed seawater were filtered under constant and gentle vacuum $(\sim 10-15 \mathrm{kPa})$ through $0.45 \mu \mathrm{m}$ pore size polycarbonate membranes. Additionally, water filtration was performed through 0.22 and $1.00 \mu \mathrm{m}$ pore sizes at all sampling locations in April, and through the $0.22 \mu \mathrm{m}$ pore size only at the ANTARES station during June-July. The particulate matter retained on the filters was then stained with pre-filtered $(0.22 \mu \mathrm{m}) 0.02 \%$ alcian blue (Sigma-Aldrich, C.I.74240) in $0.06 \%$ glacial acetic acid $(\mathrm{pH}=2.5)$; before and after staining, the filters were rinsed with pre-filtered $(0.22 \mu \mathrm{m})$ Milli-Q water. Membranes stained with alcian blue were placed in capped vials and eluted in $2 \mathrm{~mL}$ of $80 \%$ sulfuric acid for $2-3 \mathrm{~h}$. Vials were centrifuged at 1,500 rpm for $5 \mathrm{~min}$ and then the absorbance of the acid supernatant was measured at $787 \mathrm{~nm}$ with a UV-visible spectrometer (Lambda 40, Perkin-Elmer) using a $1 \mathrm{~cm}$ pathlength cell. The TEP concentrations were estimated based on a calibration derived from absorbance values of xanthan gum standards ( $\mu \mathrm{g} \mathrm{XG} \mathrm{eq} \cdot \mathrm{mL}^{-1}$ ) after processing in the same manner as above and according to the equation proposed by Villacorte et al. (2015). A rough equivalence of TEP $\left(\mu \mathrm{g} \mathrm{XG} \mathrm{eq} \cdot \mathrm{mL}^{-1}\right)$ to carbon content $\left(\mu \mathrm{g} \mathrm{C} \cdot \mathrm{mL}^{-1}\right)$ was calculated using the average factor of 0.63 proposed by Engel (2004). Depth-integrated values of carbon associated to TEP were calculated from the vertical profiles of TEP retained by the $0.45 \mu \mathrm{m}$ pore size membrane.

Quantification by epifluorescence microscopy of heterotrophic prokaryote cells (Bacteria and Archaea), hereinafter referred to as bacterioplankton, was performed using samples taken from the first 2 cruises and preserved with buffered formalin (final concentration 1\%) after staining with 4',6-diamidino-2-phenylindole (Kepner and Pratt 1994). Coupled with bacterioplankton abundances, aerobic community respiration was assessed in unfiltered samples from the ANTARES station. For this purpose, duplicate water samples were dispensed into $160 \mathrm{~mL}$ borosilicate BOD bottles and then incubated for 10-12 d. During incubation, oxygen consumption was measured in each bottle at different time intervals using planar oxygen sensitive spots (SP-PSt3-NAU-YOP) and the Fibox 4 system (PreSens, Regensburg, Germany) (Berggren et al. 2012, Villegas-Mendoza et al. 2015). In April 2016 a set of unfiltered seawater samples from the 3 locations was preserved with phosphoric acid $(0.25 \% \mathrm{~V} / \mathrm{V}$ final concentration) and frozen for total organic carbon (TOC) analysis by the high temperature combustion method through a TOC analyzer (vario TOC cube, Elementar Americas) at the Laboratory of CeMIEGeo at CICESE. Ampoulated low-carbon water and deep seawater (provided by Hansell laboratory, RSMAS/MAC University of Miami) were used as certified reference materials, which were injected before sample injection while alternating a standard between groups of samples. The relative standard deviations (CV) of 3 replicate TOC analyses were $<9 \%$ (average: $4.2 \%$ ). Statistical la distancia de la capa cuasi-isotérmica (Kara 2000), y considerando los valores del diferencial de temperatura potencial $(\Delta \theta)$ que fueron propuestos estacionalmente por Jerónimo y Gómez-Valdes (2010). Los perfiles de clorofila a (Chla) se obtuvieron indirectamente a partir de mediciones de fluorescencia que se calibraron con determinaciones espectrofotométricas en extractos de muestras discretas de la columna de agua.

La concentración de PET se evaluó colorimétricamente siguiendo el método de Passow y Alldredge (1995). Varias alícuotas de 20-100 mL de agua de mar no fijada fueron filtradas a presión de vacío constante y suave $(\sim 10-15 \mathrm{kPa})$ a través de membranas de policarbonato con tamaño de poro de $45 \mu \mathrm{m}$. Adicionalmente, se realizaron filtraciones de agua a través de tamaños de poro de 0.22 y $1.0 \mu \mathrm{m}$ en todos los sitios de muestreo en abril, y a través de un tamaño de poro de $0.22 \mu \mathrm{m}$ únicamente en la estación ANTARES durante junio-julio. Posteriormente, la materia particulada retenida por los filtros se tiñó con una solución prefiltrada $(0.22 \mu \mathrm{m})$ de azul alcián al $0.02 \%$ (Sigma-Aldrich, C.I. 74240) en ácido acético glacial al $0.06 \%(\mathrm{pH}=2.5)$; antes y después de la tinción, los filtros fueron enjuagados con agua Milli-Q prefiltrada $(0.22 \mu \mathrm{m})$. Las membranas teñidas con azul alcian se colocaron en viales tapados y se eluyeron en $2 \mathrm{~mL}$ de ácido sulfúrico al $80 \%$ durante $2-3 \mathrm{~h}$. Los viales se centrifugaron a 1,500 rpm durante 5 min y, luego, se midió la absorbancia del ácido sobrenadante a $787 \mathrm{~nm}$ con un espectrómetro UV visible (Lambda 40, Perkin Elmer) usando una celda de $1 \mathrm{~cm}$ de recorrido. Las concentraciones de PET se estimaron con base en una calibración derivada de los valores de absorbancia de suspensiones de concentración estándar de goma de xantano ( $\mu \mathrm{g} \mathrm{XG}$ eq $\cdot \mathrm{mL}^{-1}$ ) después de ser procesadas de la misma manera que las muestras; en los cálculos se utilizó la ecuación propuesta por Villacorte et al. (2015). Se estimó una equivalencia aproximada de PET $\left(\mu \mathrm{g} X \mathrm{X}\right.$ eq $\left.\cdot \mathrm{mL}^{-1}\right)$ a contenido de carbono $\left(\mu \mathrm{g} \mathrm{C} \cdot \mathrm{mL}^{-1}\right)$ utilizando el factor promedio de 0.63 propuesto por Engel (2004). Los valores integrados de carbono en la columna de agua asociados con las PET se calcularon a partir de los perfiles verticales de las PET retenidas por un tamaño de poro de $0.45 \mu \mathrm{m}$.

La cuantificación por microscopía de epifluorescencia de células procariotas heterotróficas (Bacteria y Archaea), en lo sucesivo denominadas bacterioplancton, se realizó a partir de las muestras de los 2 primeros cruceros preservadas con formalina tamponada (concentración final 1\%) después de tinción con 4',6-diamidino-2-fenilindol (Kepner y Pratt 1994). Junto con las abundancias de bacterioplancton, se evaluó la respiración de la comunidad aeróbica en muestras no filtradas de la estación ANTARES. Para este propósito, se dispensaron muestras de agua por duplicado en botellas de borosilicato BOD de $160 \mathrm{~mL}$ y luego se incubaron entre 10 y $12 \mathrm{~d}$. Durante la incubación, se midió el consumo de oxígeno en cada botella a diferentes intervalos de tiempo usando sensores planos de oxígeno (SP-PSt3-NAU-YOP) y un sistema Fibox 4 (PreSens, Regensburg, Alemania) (Berggren et al. 2012, Villegas-Mendoza et al. 2015). En abril de 2016 un grupo de muestras de agua de 
Hakspiel-Segura et al.: Transparent exopolymer particles off Baja California

analyses were performed with Statistica v10 computer software (StatSoft, Tulsa, OK; http://www.statsoft.com).

\section{Results}

\section{Hydrography and distribution of chlorophyll $a$}

Overall, all sampled locations presented similar hydrographic properties. As expected, sea surface temperature gradually increased by $\sim 2.7-3.5^{\circ} \mathrm{C}$ from February to July, and the mixed layer depth decreased especially at the more oceanic stations (Fig. 1). An exception to this pattern was observed mainly in April, in the upper layer of the ENSENADA station, where the mixed layer depth was shallower (5.2 m), temperatures were lower (average: $14.8^{\circ} \mathrm{C}$ ), and seawater was denser (average: 24.8) than at the stations distant from the coast (Fig. 1a-c). This feature was attributed to a larger influence of upwelling processes over this period.

The Chla profiles derived from fluorescence measurements generally showed lowest values in February (from undetectable to $0.78 \mu \mathrm{g} \cdot \mathrm{L}^{-1}$ ) and a temporal increase in the magnitude and shallowing of the deep Chla maximum (DCM) from this month onward (Fig. 2). The deepest DCMs were detected at around $15 \mathrm{~m}\left(5.64 \mu \mathrm{g} \cdot \mathrm{L}^{-1}\right)$ in April at the MICMAR station and $21 \mathrm{~m}\left(2.74 \mu \mathrm{g} \cdot \mathrm{L}^{-1}\right)$ in June-July at IMECOCAL station 100.30, whereas at the ANTARES station, DCM was located at $41 \mathrm{~m}\left(0.47 \mu \mathrm{g} \cdot \mathrm{L}^{-1}\right)$ and at $15 \mathrm{~m}$ $\left(2.29 \mu \mathrm{g} \cdot \mathrm{L}^{-1}\right)$ in April and June-July, respectively (Fig. 2b, c). The ENSENADA station was characterized by a shallower DCM, with relatively low Chla values at around $8 \mathrm{~m}$ depth in April $\left(0.94 \mu \mathrm{g} \cdot \mathrm{L}^{-1}\right)$ and June-July $\left(1.21 \mu \mathrm{g} \cdot \mathrm{L}^{-1}\right)$. Chla remained relatively high throughout the first $18 \mathrm{~m}$ depth at Todos Santos Bay (Fig. 2c).

\section{Comparison between TEP retained by different pore sizes}

The comparison between the amounts of TEP retained by the different pore sizes of membranes in April and June-July showed large differences that were confirmed by a nonparametric signed-rank test for the combinations of 2 related sets of data (Wilcoxon, $Z=2.84, n=15$ and $Z=4.20, n=23$ for $0.45 \mu \mathrm{m} v s 1.0 \mu \mathrm{m}$ and $0.45 \mu \mathrm{m} v s 0.22 \mu \mathrm{m}$, respectively; $P<0.05)$. The concentration of alcian blue stainable particles collected by the $0.2 \mu \mathrm{m}$ pore size was 1.7 to 64.0 fold (average: 11.4 fold; median: 4.1 ) and 3.0 to 37.0 fold (average: 15.7 fold; median: 8.8) higher than those retained (when they were detectable) by the 0.4 and $1.0 \mu \mathrm{m}$ pore sizes, respectively (Fig. 3a-c). Only a weak but significant correlation of TEP concentrations retained by filters of 0.22 and $1.0 \mu \mathrm{m}$ of pore sizes was detected $\left(R^{2}=0.31, n=15, P<0.05\right)$.

\section{TEP dynamics}

TEP estimated from the material retained by the operational $0.45 \mu \mathrm{m}$ pore diameter ranged from undetectable to mar sin filtrar de los 3 lugares fue preservado con ácido fosfórico $(0.25 \% \mathrm{~V} / \mathrm{V}$ de concentración final) y congelado para determinar el carbono orgánico total (COT) mediante el método de combustión a alta temperatura a través de un analizador COT (vario TOC cube, Elementar Americas) en el laboratorio de CeMIEGeo del CICESE. Se utilizaron ampolletas de agua con bajo contenido de carbono y agua de mar profunda (proporcionadas por el laboratorio Hansell, RSMAS/MAC de la Universidad de Miami) como materiales de referencia certificados, que se inyectaron antes de la inyección de la muestra alternando un estándar de concentración conocida entre los grupos de muestras. Las desviaciones estándar relativas (CV) de 3 análisis de COT repetidos fueron $<9 \%$ (promedio: $4.2 \%$ ). Los análisis estadísticos se realizaron con el software informático Statistica v10 (StatSoft, Tulsa, OK; http://www.statsoft.com).

\section{Resultados}

\section{Hidrografía y distribución de clorofila a}

En general, todos los sitios de muestreo presentaron propiedades hidrográficas similares. Tal como se esperaba, de febrero a julio la temperatura superficial del mar aumentó gradualmente en $\sim 2.7-3.5^{\circ} \mathrm{C}$ y la profundidad de la capa mixta disminuyó, especialmente en las estaciones más oceánicas (Fig. 1). Una excepción a este patrón se observó en la capa superficial de la estación ENSENADA durante abril, cuando se presentaron una profundidad de la capa de mezcla más superficial $(5.2 \mathrm{~m})$, temperaturas más bajas (promedio: $14.8^{\circ} \mathrm{C}$ ) y agua de mar más densa (promedio: 24.8 ) respecto a estaciones alejadas de la costa (Fig. 1a-c). Esta característica se atribuyó a una mayor influencia de los eventos de surgencia durante este periodo.

Los perfiles de Chla derivados de las mediciones de fluorescencia generalmente mostraron valores más bajos en febrero (de indetectable a $0.78 \mu \mathrm{g} \cdot \mathrm{L}^{-1}$ ), así como un aumento temporal de la magnitud y la disminución del máximo profundo de Chla (MPC) a partir de este mes (Fig. 2). Los MPC más profundos se detectaron a alrededor de $15 \mathrm{~m}\left(5.64 \mu \mathrm{g} \cdot \mathrm{L}^{-1}\right)$ en abril en la estación MICMAR y $21 \mathrm{~m}\left(2.74 \mu \mathrm{g} \cdot \mathrm{L}^{-1}\right)$ en junio-julio en la estación IMECOCAL 100.30, mientras que en la estación ANTARES los MPC se detectaron a $41 \mathrm{~m}$ $\left(0.47 \mu \mathrm{g} \cdot \mathrm{L}^{-1}\right)$ y a $15 \mathrm{~m}\left(2.29 \mu \mathrm{g} \cdot \mathrm{L}^{-1}\right)$ en abril y junio-julio, respectivamente (Fig. 2b, c). La estación ENSENADA se caracterizó por presentar un MPC más somero, con valores de Chla relativamente bajos a $\sim 8 \mathrm{~m}$ de profundidad tanto en abril $\left(0.94 \mu \mathrm{g} \cdot \mathrm{L}^{-1}\right)$ como en junio-julio $\left(1.21 \mu \mathrm{g} \cdot \mathrm{L}^{-1}\right)$. La Chla se mantuvo relativamente alta a lo largo de los primeros $18 \mathrm{~m}$ de profundidad en la bahía de Todos Santos (Fig. 2c).

\section{Comparación entre las PET retenidas por diferentes tamaños de poro}

La comparación entre las cantidades de PET retenidas por los diferentes tamaños de poro de las membranas en 

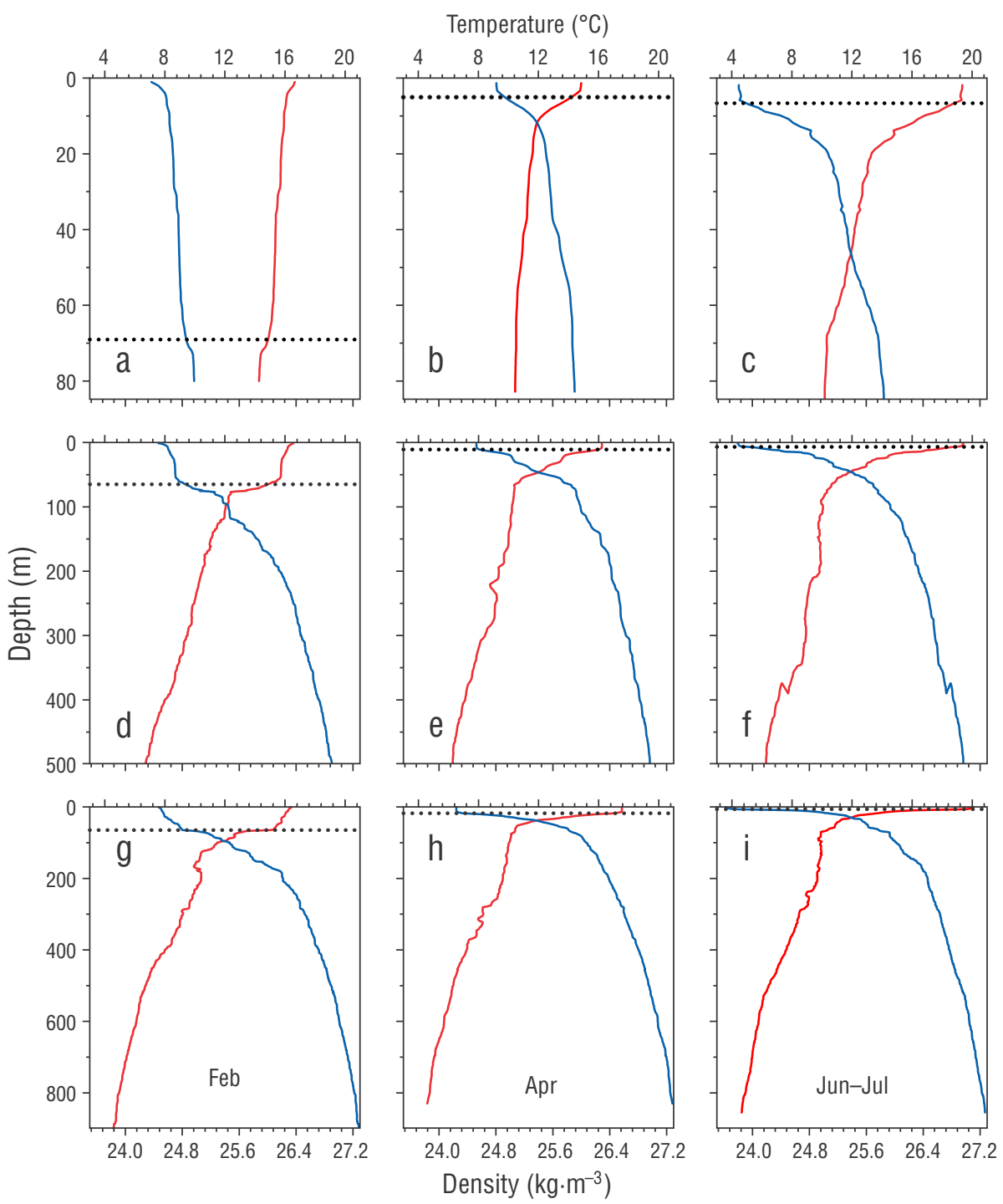

Figure 1. Vertical profiles of temperature (red line) and density (blue line) at the stations ENSENADA (a-c), MICMAR (d-e), IMECOCAL 100.30 (f), and ANTARES (g-i) during the cruises conducted in February, April, and June-July 2016. Dashed line corresponds to mixed layer depth.

Figura 1. Perfiles verticales de temperatura (línea roja) y densidad (línea azul) en las estaciones ENSENADA (a-c), MICMAR (d-e), IMECOCAL 100.30 (f) y ANTARES (g-i) en los cruceros de febrero, abril y junio-julio de 2016. La línea discontinua corresponde a la profundidad de la capa de la mezcla.

$7.18 \mu \mathrm{g} \mathrm{XG} \mathrm{eq} \cdot \mathrm{mL}^{-1}$ (average: $1.13 \mu \mathrm{g} \mathrm{XG} \mathrm{eq} \cdot \mathrm{mL}^{-1}$; median: $\left.0.70 \mu \mathrm{g} \mathrm{XG} \mathrm{eq} \cdot \mathrm{mL}^{-1}\right)$, with the lowest concentrations in February at the offshore and deeper stations (ANTARES and MICMAR) and the highest in June-July at mostly all sampled sites, especially at the shallower and nearshore stations (the Todos Santos Bay station and the ENSENADA station, lower panel in Fig. 3). High TEP concentrations were also detected in February in the water column of the ENSENADA station (Fig. 3a*). The vertical TEP distribution showed a slight tendency to decrease with depth at most stations, although higher variability within data from the ENSENADA and MICMAR stations was predominantly observed in February (CV range: 47-194\%). abril y junio-julio mostró diferencias marcadas que fueron confirmadas por una prueba no paramétrica de rangos para las combinaciones de 2 conjuntos de datos relacionados (Wilcoxon, $Z=2.84, n=15$ y $Z=4.20, n=23$ para $0.45 \mu \mathrm{m}$ frente a $1.0 \mu \mathrm{m}$ y $0.45 \mu \mathrm{m}$ frente a $0.22 \mu \mathrm{m}$, respectivamente; $P<0.05)$. La concentración de partículas teñidas con azul alcián, recolectadas por el tamaño de poro de $0.2 \mu \mathrm{m}$ fue de 1.7 a 64 veces (promedio: 11.4 veces; mediana: 4.1) y de 3 a 37 veces (promedio: 15.7 veces; mediana: 8.8 ) mayor que las concentraciones retenidas (cuando fueron detectables) a través de los tamaños de poro de 0.4 y $1.0 \mu \mathrm{m}$, respectivamente (Fig. 3a-c). Sólo se detectó una correlación débil pero significativa de las concentraciones de PET retenidas por 


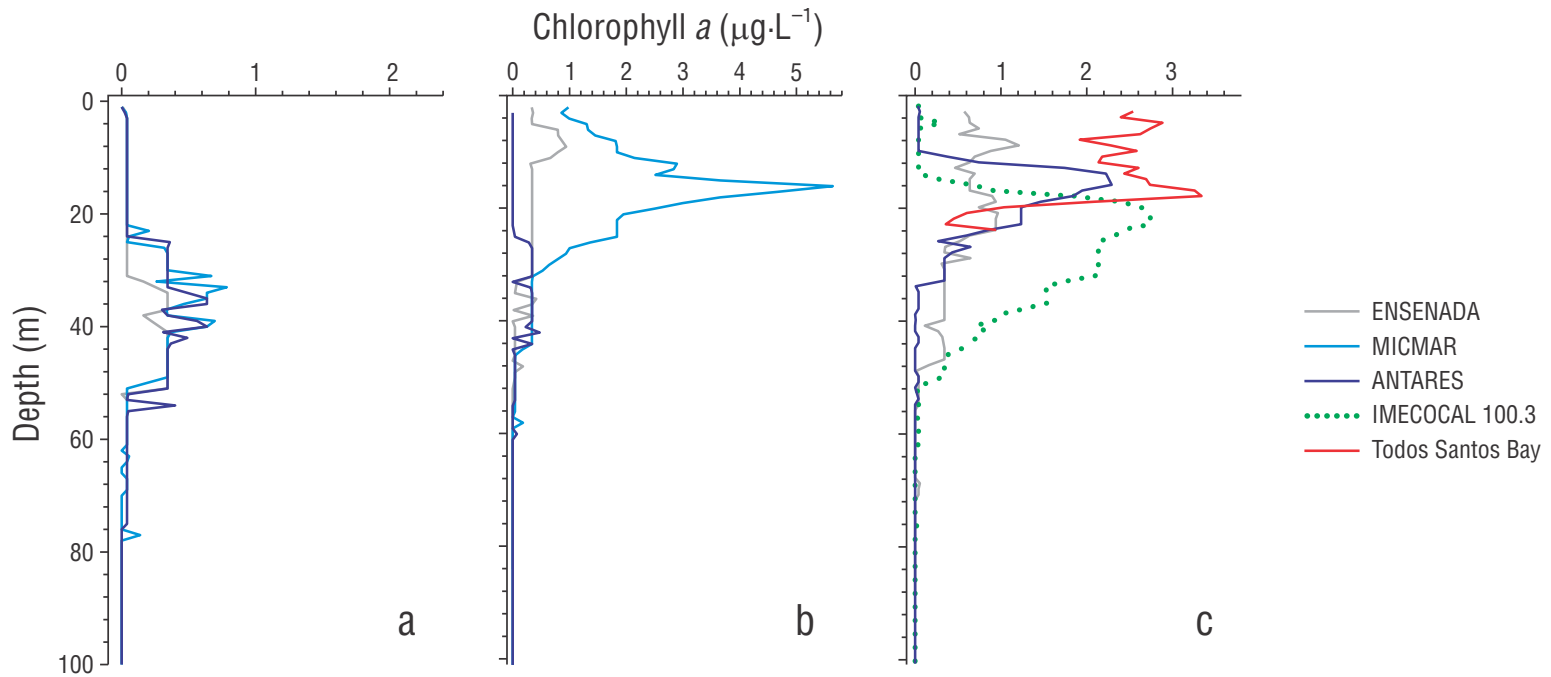

Figure 2. Vertical profiles of chlorophyll $a$ derived from fluorescence measurements at the sampling stations in February (a), April (b), and June-July 2016 (c).

Figura 2. Perfiles verticales de clorofila $a(\mathrm{Chl} a)$ derivados de las mediciones de fluorescencia en las estaciones de muestreo en febrero (a), abril (b) y junio-julio de 2016 (c).
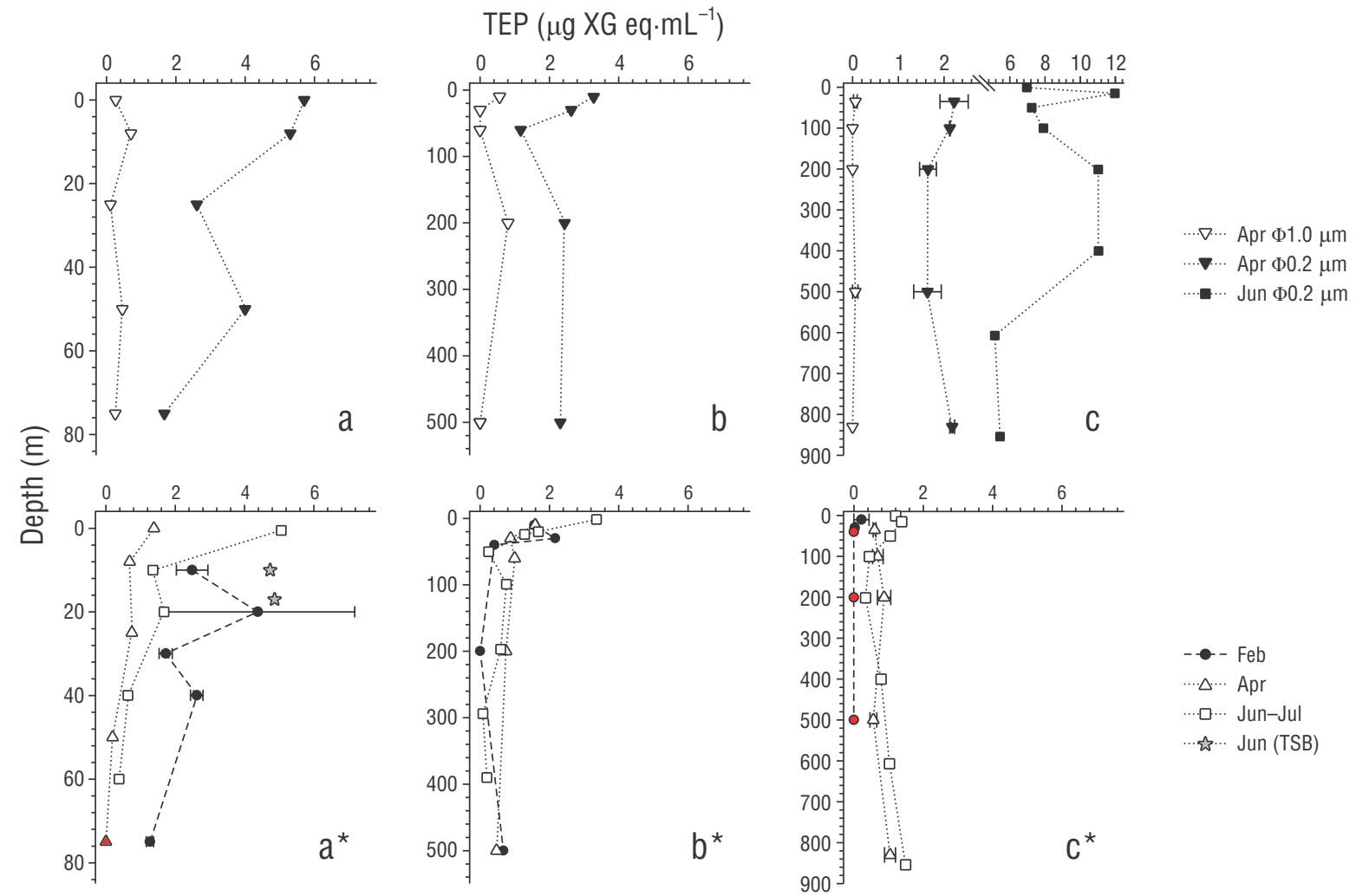

Figure 3. Vertical profiles of transparent exopolymer particles (TEP) at the stations ENSENADA and Todos de Santos Bay (TSB; a, a*), MICMAR and IMECOCAL $100.30\left(\mathbf{b}, \mathbf{b}^{*}\right)$, and ANTARES $\left(\mathbf{c}, \mathbf{c}^{*}\right)$. Profiles in the upper panel correspond to TEP retained by nominal pore sizes of 0.2 and $1.0 \mu \mathrm{m}$ in samples from April and June-July 2016. Profiles with asterisk in the lower panel correspond to TEP retained by the operational pore size $(0.45 \mu \mathrm{m})$ during the 3 cruises. Error bars indicate standard error. Red color on symbols means undetectable value.

Figura 3. Perfiles verticales de partículas de exopolímeros transparentes (TEP) en las estaciones ENSENADA y bahía de Todos Santos (TSB; $\left.\mathbf{a}, \mathbf{a}^{*}\right)$, MICMAR e IMECOCAL $100.30\left(\mathbf{b}, \mathbf{b}^{*}\right)$ y ANTARES $\left(\mathbf{c}, \mathbf{c}^{*}\right)$. Los perfiles en el panel superior corresponden a las TEP retenidas por un tamaño de poro nominal de 0.2 y $1.0 \mu \mathrm{m}$ en muestras de abril y junio-julio de 2016 . Los perfiles con asterisco $(*)$ del panel inferior corresponden a las TEP retenidas por el tamaño de poro operativo $(0.45 \mu \mathrm{m})$ durante los 3 cruceros. Las barras de error indican el error estándar. El color rojo de los símbolos indica un valor indetectable. 

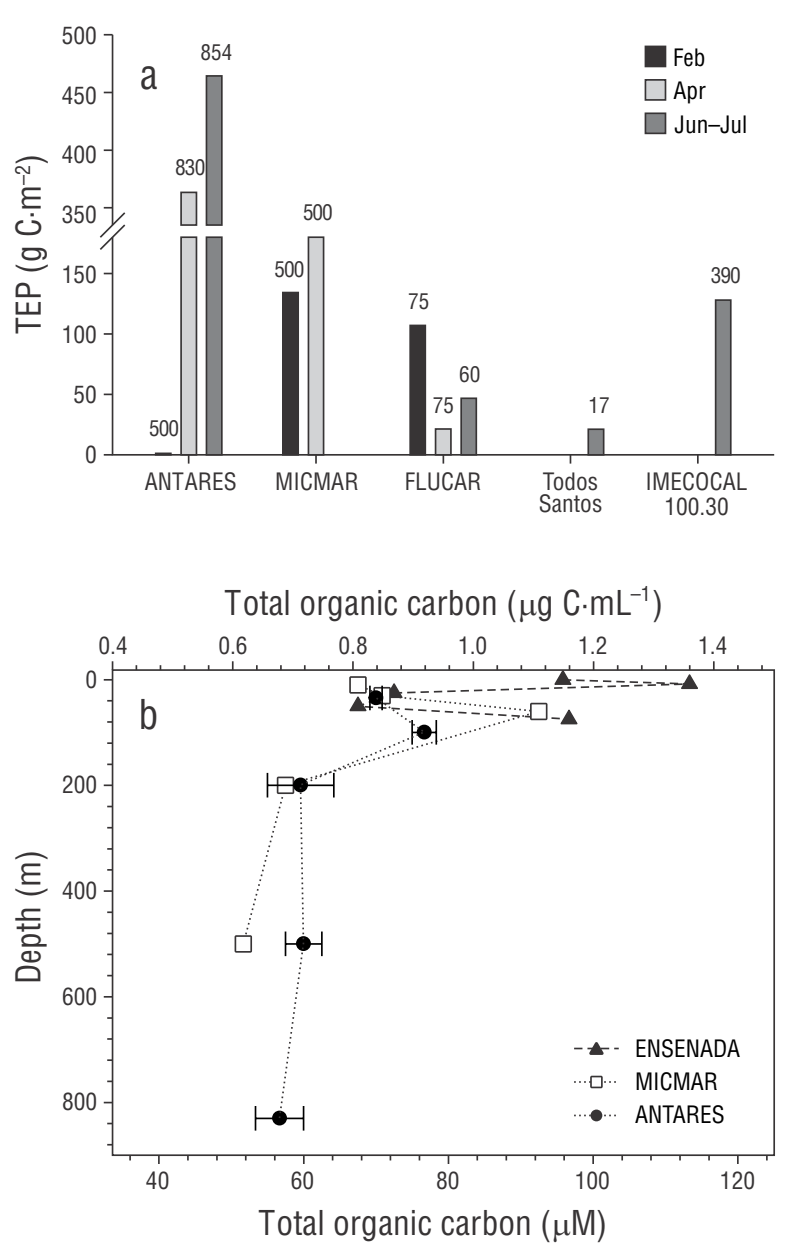

Figure 4. Temporal dynamics of depth-integrated carbon concentration in relation to transparent exopolymer particles (TEP) retained by $0.45 \mu \mathrm{m}$ pore size (a) and vertical profiles of total organic carbon in April 2016 (b). Vertical number over the bar represents the depth of integration. Error bars indicate standard error.

Figura 4. Dinámica temporal de la concentración integrada de carbono asociada a las partículas de exopolímeros transparentes (TEP) retenidas por un tamaño de poro de $0.45 \mu \mathrm{m}$ (a) y perfiles verticales de carbono orgánico total en abril de 2016 (b). El número vertical sobre la barra representa la profundidad de la integración. Las barras de error indican el error estándar.

At the ANTARES station, depth-integrated TEP concentrations (expressed as grams of carbon per square meter) varied temporally by $\sim 88 \%$ (from $\sim 1$ to $464 \mathrm{~g} \mathrm{C} \cdot \mathrm{m}^{-2}$, highest value recorded in June-July), whereas this variation was $\sim 21 \%$ and $80 \%$ at the MICMAR station $\left(\sim 134\right.$ to $\left.181 \mathrm{~g} \mathrm{C} \cdot \mathrm{m}^{-2}\right)$ and the ENSENADA station $\left(\sim 17\right.$ to $\left.107 \mathrm{~g} \mathrm{C} \cdot \mathrm{m}^{-2}\right)$, respectively. Depth-integrated TEP concentrations followed an increasing trend toward summer except at the ENSENADA station, which showed relatively similar values in February and June-July (Fig. 4a). A rough estimate of depth-integrated TEP in the upper layer (considering the available samples from $<100 \mathrm{~m}$ depth) revealed a moderately low contribution to the sampled water column at the ANTARES filtros con tamaño de poro de 0.22 y $1.0 \mu \mathrm{m}\left(R^{2}=0.31, n=\right.$ $15, P<0.05)$.

\section{Dinámicas de las PET}

Las PET estimadas a partir del material retenido por el diámetro de poro operativo de $0.45 \mu \mathrm{m}$ oscilaron entre indetectable y $7.18 \mu \mathrm{g} \mathrm{XG} \mathrm{eq \cdot} \cdot \mathrm{mL}^{-1}$ (promedio: $1.13 \mu \mathrm{g} \mathrm{XG} \mathrm{eq \cdot} \cdot \mathrm{mL}^{-1}$;

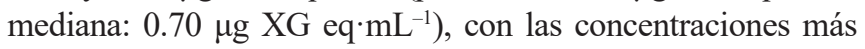
bajas en febrero en las estaciones más alejadas de la costa y más profundas (estaciones ANTARES y MICMAR) y las más altas en junio-julio en la mayoría de los sitios de muestreo, especialmente en las estaciones más someras y cercanas a la costa (la estación de la bahía de Todos Santos y la estación ENSENADA; panel inferior en Fig. 3). Las concentraciones altas de PET en la columna de agua también se detectaron en febrero en la estación ENSENADA (Fig. 3a*). La distribución vertical de las PET mostró una ligera tendencia a disminuir con la profundidad en la mayoría de las estaciones, aunque se observó una mayor variabilidad (intervalo CV: 47-194\%) en los datos de las estaciones ENSENADA y MICMAR predominantemente en febrero.

En la estación ANTARES, las concentraciones integradas de PET (expresadas en carbono por metro cuadrado) variaron temporalmente en $\sim 88 \%$ ( $\mathrm{de} \sim 1 \mathrm{a} 464 \mathrm{~g} \mathrm{C} \cdot \mathrm{m}^{-2}$; valor más alto registrado en junio-julio), mientras que esta variación fue de $\sim 21 \%$ y $80 \%$ en la estación MICMAR $\left(\sim 134 \mathrm{a} 181 \mathrm{~g} \mathrm{C} \cdot \mathrm{m}^{-2}\right)$ y en la estación ENSENADA $\left(\sim 17\right.$ a $\left.107 \mathrm{~g} \mathrm{C} \cdot \mathrm{m}^{-2}\right)$, respectivamente. Las concentraciones integradas de PET siguieron una tendencia al aumento hacia el verano, excepto en la estación ENSENADA, que presentó valores relativamente similares en febrero y junio-julio (Fig. 4a). Una estimación aproximada de las PET integradas para la capa superficial (considerando las muestras disponibles de $<100 \mathrm{~m}$ de profundidad) reveló una contribución moderadamente baja a la columna de agua en la estación ANTARES en abril $(\sim 7 \%)$ y julio (14\%), y en la estación MICMAR en febrero ( $27 \%)$ y abril (13\%). Esta contribución fue considerablemente mayor en febrero en la estación ANTARES $(\sim 100 \%)$ y en junio-julio en la estación IMECOCAL 100.30 (43\%). En términos de contenido de carbono, la estación ENSENADA, generalmente, presentó las mayores concentraciones integradas (promedio: $39 \pm 15 \mathrm{~g} \mathrm{C} \cdot \mathrm{m}^{-2}$ ) en la capa superficial, excepto en junio-julio, cuando los contenidos de carbono en las estaciones ANTARES $\left(63 \mathrm{~g} \mathrm{C} \cdot \mathrm{m}^{-2}\right)$ e IMECOCAL $100.30\left(55 \mathrm{~g} \mathrm{C} \cdot \mathrm{m}^{-2}\right)$ fueron máximos.

Como se observó para la distribución de las PET, el COT mostró diferencias bien definidas entre los lugares, lo cual reveló una mayor concentración de COT en las estaciones ENSENADA y MICMAR que en la estación ANTARES (Fig. 4b). Las concentraciones de COT en abril (intervalo: 0.63 a $1.33 \mu \mathrm{g} \mathrm{C} \cdot \mathrm{mL}^{-1}$; promedio: $0.87 \mu \mathrm{g} \mathrm{C} \cdot \mathrm{mL}^{-1}$ ) fueron de $\sim 1.3$ a 6.8 veces mayores (Wilcoxon; $Z=3.61, n=$ $15, P>0.05)$ que el contenido de carbono obtenido indirectamente de las PET (intervalo: indetectable a $0.87 \mu \mathrm{g} \mathrm{C} \cdot \mathrm{mL}^{-1}$; 
Hakspiel-Segura et al.: Transparent exopolymer particles off Baja California

station in April ( $7 \%)$ and July (14\%) and at the MICMAR station in February ( 27\%) and April (13\%). This contribution was considerably larger in February at the ANTARES station $(\sim 100 \%)$ and in June-July at IMECOCAL 100.30 $(43 \%)$. In terms of carbon content, the ENSENADA station predominately showed the highest integrated concentrations (average: $39 \pm 15 \mathrm{~g} \mathrm{C} \cdot \mathrm{m}^{-2}$ ) in the upper layer, except in June-

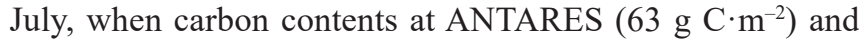
IMECOCAL $100.30\left(55 \mathrm{~g} \mathrm{C} \cdot \mathrm{m}^{-2}\right)$ were maxima.

As observed for the TEP distribution, TOC showed well-defined differences between locations, revealing higher TOC concentrations at the ENSENADA and MICMAR stations than at the ANTARES station (Fig. 4b). TOC concentrations in April (range: 0.63 to $1.33 \mu \mathrm{g} \mathrm{C} \cdot \mathrm{mL}^{-1}$, average: $0.87 \mu \mathrm{g} \mathrm{C} \cdot \mathrm{mL}^{-1}$ ) were $\sim 1.3$ to 6.8 fold higher (Wilcoxon; $Z=$ $3.61, n=15, P>0.05)$ than the TEP carbon content concentrations (range: undetectable to $0.87 \mu \mathrm{g} \mathrm{C} \cdot \mathrm{mL}^{-1}$; average: $0.43 \mu \mathrm{g} \mathrm{C} \cdot \mathrm{mL}^{-1}$ ) indirectly obtained from the same samples filtered through the $0.45 \mu \mathrm{m}$ pore size.

\section{Rates of community aerobic respiration and bacterioplankton abundance}

The community respiration rates ranged from 1.45 to $5.88 \mu \mathrm{M} \mathrm{O}_{2} \cdot \mathrm{d}^{-1}$ (average: $3.33 \pm 1.39 \mu \mathrm{M} \mathrm{O}_{2} \cdot \mathrm{d}^{-1}$ ) with greater values in February (average: $3.75 \pm 1.03 \mu \mathrm{M} \mathrm{O}_{2} \cdot \mathrm{d}^{-1}$ ) than in April (average: $2.21 \pm 0.46 \mu \mathrm{M} \mathrm{O}_{2} \cdot \mathrm{d}^{-1}$ ). There was no clear vertical pattern, although relatively high rates were observed in the upper $100 \mathrm{~m}$ depth (Fig. 5a). Bacterioplankton abundance ranged from $7.84 \times 10^{4}$ to $1.87 \times 10^{6}$ cells $\cdot \mathrm{mL}^{-1}$ (average: $7.84 \times 10^{5}$ cells $\cdot \mathrm{mL}^{-1}$ ). This biological variable showed high values at the surface and eventually the subsurface close to the DCM, with a pronounced tendency to decline with depth. Abundances from April were generally higher than those from February, except for some subsurface values at the ENSENADA station. In the uppermost layers, the ENSENADA station showed the highest abundance followed by MICMAR. However, in April, abundances below $8 \mathrm{~m}$ depth were relatively higher at the offshore stations (Fig. 5b, c).

\section{DisCUSSION}

\section{Comparison between TEP retained by different pore sizes}

Filtration is a crucial and critical step during analyses of particulate and dissolved material in most studies of seawater. Although this study focused on the first description of TEP concentrations in the North Pacific off Baja California, we made some comparisons between the concentrations obtained with the operational pore size $(0.45 \mu \mathrm{m})$ established by the original method (Alldredge et al. 1993) and those obtained with 2 other pore sizes in order to expose the potential bias that may occur when the nature of this organic compounds allows for self-assembling or disaggregation in promedio: $0.43 \mu \mathrm{g} \mathrm{C} \cdot \mathrm{mL}^{-1}$ ) a partir de las mismas muestras filtradas con un tamaño de poro de $0.45 \mu \mathrm{m}$.

Tasas de respiración aeróbica comunitaria y abundancia de bacterioplancton

Las tasas de respiración de la comunidad fluctuaron de 1.45 a $5.88 \mu \mathrm{M} \mathrm{O}_{2} \cdot \mathrm{d}^{-1}$ (promedio: $3.33 \pm 1.39 \mu \mathrm{M} \mathrm{O}_{2} \cdot \mathrm{d}^{-1}$ ) con mayores valores en febrero (promedio: $3.75 \pm 1.03 \mu \mathrm{M} \mathrm{O}_{2} \cdot \mathrm{d}^{-1}$ ) que en abril (promedio: $2.21 \pm 0.46 \mu \mathrm{M} \mathrm{O}_{2} \cdot \mathrm{d}^{-1}$ ). No hubo un patrón vertical claro, aunque se observaron tasas relativamente altas en los primeros $100 \mathrm{~m}$ de profundidad (Fig. 5a). La abundancia de bacterioplancton osciló entre $7.84 \times 10^{4}$ y $1.87 \times 10^{6}$ cél $\cdot \mathrm{mL}^{-1}$ (promedio: $7.84 \times 10^{5}$ ). Esta variable biológica presentó altos valores en la superficie y eventualmente en la subsuperficie cerca de la MPC, con una fuerte tendencia a disminuir con la profundidad. Las abundancias de abril, generalmente, fueron más altas que las de febrero, a excepción de algunos valores en la subsuperficie en la estación ENSENADA. En las capas más superficiales, la estación ENSENADA presentó la máxima abundancia seguida por MICMAR. Sin embargo, en abril, las abundancias por debajo de $8 \mathrm{~m}$ de profundidad fueron relativamente mayores en las estaciones alejadas de la costa (Fig. 5b, c).

\section{Discusión}

\section{Comparación entre las PET retenidas por diferentes tamaños de poro}

La filtración es un paso crucial y crítico durante los análisis de partículas y material disuelto en la mayoría de los estudios del agua de mar. Aunque este estudio se centró en realizar una primera descripción de las concentraciones de PET en el Pacífico Norte frente a Baja California, se realizaron algunas comparaciones entre las concentraciones obtenidas con el tamaño de poro operacional $(0.45 \mu \mathrm{m})$ establecido por el método original (Alldredge et al. 1993) y aquellas obtenidas con otros 2 tamaños de poro para exponer el sesgo potencial que puede ocurrir cuando la naturaleza de estos compuestos orgánicos permite el autoensamblaje o desagregación en el rango inferior del material particulado $(>0.4 \mu \mathrm{m})$ o de las PET coloidales $(0.05$ a $0.45 \mu \mathrm{m})$. En algunos experimentos con cultivos de tipo discontinuos de Alexandrium tamarense, Chaetoceros affinis y Microcystis sp., Villacorte et al. (2015) demostraron que la producción de PET en mediciones continuas se mantuvo generalmente entre el $\sim 11 \%$ y $\sim 23 \%$ de la fracción total de PET más los precursores de las PET $(10 \mathrm{kDa}$ a $0.4 \mu \mathrm{m})$. En general, los resultados obtenidos a partir de nuestro estudio revelaron que la concentración promedio de partículas teñidas con azul alcián retenidas con un tamaño de poro de $0.2 \mu \mathrm{m}$ fue $\sim 79 \%$ y $~ 93 \%$ más alta que la concentración obtenida con tamaños de poro de 0.4 y $1.0 \mu \mathrm{m}$, respectivamente. Estos porcentajes son relativamente más altos comparados con algunos valores promedio 


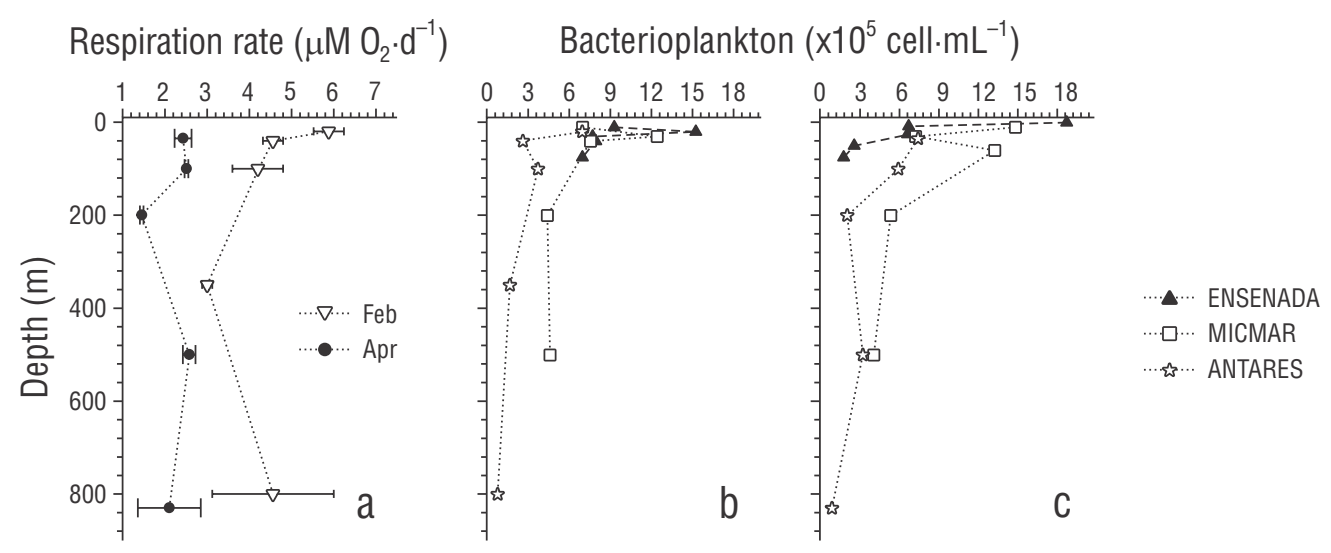

Figure 5. Vertical profiles of rates of aerobic community respiration in February and April 2016 at ANTARES (a) and bacterial abundances in February (b) and April (c) 2016 at the stations ENSENADA, MICMAR and ANTARES. Error bars indicate standard error.

Figura 5. Perfiles verticales de las tasas de respiración aeróbica de la comunidad en ANTARES en febrero y abril de 2016 (a) y abundancia bacteriana en las estaciones ENSENADA, MICMAR y ANTARES en febrero (b) y abril (c) de 2016 . Las barras de error indican el error estándar.

the lower range of particulate material $(>0.4 \mu \mathrm{m})$ or colloidal TEP $(0.05$ to $0.45 \mu \mathrm{m})$. In some experiments with batch cultures of Alexandrium tamarense, Chaetoceros affinis, and Microcystis sp., Villacorte et al. (2015) demonstrated that continuous production measurements of TEP were generally between $\sim 11 \%$ and $\sim 23 \%$ of the whole fraction of TEP plus TEP precursors $(10 \mathrm{kDa}-0.4 \mu \mathrm{m})$. In general, the results obtained from our study revealed that the average concentration of alcian blue stainable particles collected by the $0.2 \mu \mathrm{m}$ pore size was $\sim 79 \%$ and $\sim 93 \%$ higher than that collected by the 0.4 and 1.0 pore sizes, respectively. These percentages are relatively higher compared with some average values $(\sim 42-50 \%)$ reported for coastal and estuarine systems (Passow and Alldredge 1995, Sun et al. 2012). The relative importance of this small fraction is consistent with several studies implementing different microscopy techniques coupled with image analysis and energy-dispersive $\mathrm{X}$-ray spectroscopy, which estimated large concentrations of small colloids $(0.005$ to $0.2 \mu \mathrm{m})$ in seawater ranging from $\sim 10^{7}$ to $10^{9}$ particles per milliliter (Koike et al. 1990, Wells and Goldberg 1991). Using oceanic samples (surface, 1,600 and 2,600 $\mathrm{m}$ depth) collected by cross-flow ultrafiltration in the Gulf of Mexico and Middle Atlantic Bight, Santschi et al. (1998) demonstrated high prevalence of macromolecules and colloids rich in polysaccharides ranging from 0.001 to $0.200 \mu \mathrm{m}$ in legth, as well as showing an important size fraction of fibrillar polysaccharides measuring $1.0-3.0 \mathrm{~nm}$ in diameter and $0.1-2.0 \mu \mathrm{m}$ long. Analyses of size classes of TEP in samples from estuarine and coastal waters off Netherlands and Belgium revealed that $\sim 36-90 \%$ of TEP concentrations (ranging from $\sim 0.5$ to $1.6 \mu \mathrm{g} \mathrm{XG} \mathrm{eq} \cdot \mathrm{mL}^{-1}$ ) corresponded to the colloidal fraction (Villacorte et al. 2009).

The lack of a significant relationship between alcian blue stainable particles in size fractions $>0.22 \mu \mathrm{m}$ and $>0.45 \mu \mathrm{m}$ $(\sim 42-50 \%)$ reportados para sistemas costeros y estuarinos (Passow y Alldredge 1995, Sun et al. 2012). La importancia relativa de esta pequeña fracción es consistente con varios estudios que implementan diferentes técnicas de microscopía acopladas con análisis de imágenes y espectroscopía de rayos $\mathrm{X}$ de energía dispersiva, los cuales estimaron una alta concentración de pequeños coloides $(0.005$ a $0.2 \mu \mathrm{m})$ en agua de mar que osciló entre $\sim 10^{7}$ y $10^{9}$ partículas por mililitro (Koike et al. 1990, Wells y Goldberg 1991). Con muestras oceánicas recolectadas por ultrafiltración de flujo cruzado en el golfo de México y la ensenada del Atlántico medio (superficie, 1,600 y 2,600 m de profundidad), Santschi et al. (1998) demostraron una alta prevalencia de macromoléculas y coloides ricos en polisacáridos con longitudes de 0.001 a $0.200 \mu \mathrm{m}$, así como una importante fracción de tamaño de polisacáridos fibrilares con un diámetro de 1.0-3.0 nm y una longitud de 0.1-2.0 $\mu \mathrm{m}$. Otros análisis de fracciones por tamaño de PET en muestras de aguas estuarinas y costeras de Holanda y Bélgica revelaron que entre el $\sim 36 \%$ y $90 \%$ de las concentraciones de PET

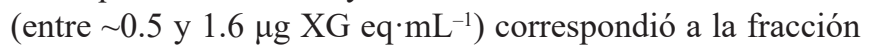
coloidal (Villacorte et al. 2009).

La ausencia de una relación significativa entre las partículas teñidas con azul alcián en las fracciones de tamaño $>0.22 \mu \mathrm{m}$ y $>0.45 \mu \mathrm{m}$ indica diferencias sustanciales entre la interacción dinámica de partículas grandes y partículas coloidales, puesto que tienen una vida relativamente corta y están sujetas a altas tasas de recambio (ensamblaje/dispersión) en la columna de agua (Verdugo 2012). Algunos enfoques experimentales sugieren que la masa de los precursores de PET $(>0.2 \mu \mathrm{m})$ es mucho mayor bajo condiciones de estancamiento que bajo condiciones turbulentas (Stoderegger y Herndl 1999). Así, el uso de membranas con un tamaño de poro más pequeño, como $0.2 \mu \mathrm{m}$, podría aumentar la efectividad para retener una fracción de coloides teñibles a mayor profundidad, e incluso en sitios bajo condiciones limitantes de 
indicates substantial differences between the dynamic interaction of large particles and colloidal particles, since they have a relatively short lifespan and are subject to high rates of assembly/dispersion turnover in the water column (Verdugo 2012). Some experimental approaches suggest that the mass of TEP precursors $(>0.2 \mu \mathrm{m})$ is much higher under stagnant than under turbulent conditions (Stoderegger and Herndl 1999). Thus, the use of a membrane with a smaller pore size (e.g., $0.2 \mu \mathrm{m}$ ) could increase sensitivity to collect a fraction of stainable colloids at greater depths and even in places under nutrient-depleted conditions. However, we do not discard the possibility that the shape and the amount of TEP precursors in the seawater sample could influence filtration efficiency through the clogging of membrane pores and thus the breakdown or assembly thereof. In addition, cell lysis may also contribute to the formation of new stainable substances on the filters as a result of the increased pressure during filtration (Discart et al. 2015).

\section{TEP and environmental and biological variables}

The California Current System off Baja California is considered to be highly dynamic in terms of seasonal and spatial fluctuations of primary production (Hernández de La Torre et al. 2004, Kahru et al. 2009, Gaxiola-Castro et al. 2010, Martínez-Gaxiola et al. 2010). Part of this variability originates from environmental gradients between the coast and the open ocean and also along mesoscale processes (Santamaria-del-Angel et al. 2002, Barocio-León et al. 2007). At the beginning of this research, we aimed to describe the TEP concentration to elucidate how it is influenced temporally and spatially by environmental properties and primary production off northern Baja California. In this area, the incidence of intense upwelling from April to June promotes an increase in the concentration of inorganic nutrients in surface and subsurface layers (Pérez-Brunius et al. 2007, Durazo 2015) that stimulates the growth and accumulation of macroalgal and phytoplankton biomass (Martínez-Gaxiola et al. 2010, Cruz-Trejo et al. 2015). During the study period upwelling was strongest in April, as indicated by a shallowing of the mixed layer depth and the thermocline, and the cooling of the surface layer at the stations nearest to the coast. Biological evidence of upwelling processes was also noted through the Chla dynamics and shallowing of the DCM at the stations closest to shore (Millán-Nuñez et al. 1997). This behavior coincides well with some satellite observations of sea surface temperature and ocean color, and with upwelling indices (e.g., Espinosa-Carreón et al. 2004, Gómez-Ocampo et al. 2017).

Our data showed relatively high concentrations of TEP $>0.45 \mu \mathrm{m}\left(>0.3 \mu \mathrm{g} \mathrm{XG} \mathrm{eq} \cdot \mathrm{mL}^{-1}\right)$, even at greater depths, compared to other published concentrations for the open ocean and coastal and estuarine environments (Wetz et al. 2009, Malpezzi et al. 2013, Annane et al. 2015, Benavides et al. 2015). Most field studies have shown increased nutrientes. Sin embargo, no descartamos la posibilidad de que la forma y la cantidad de los precursores de PET en la muestra de agua de mar puedan influir en la eficiencia de la filtración a través de la obstrucción de los poros de la membrana y, por lo tanto, en la ruptura o ensamblaje de los mismos. Aunado a lo anterior, un aporte potencial de nuevas sustancias coloreables en los filtros derivada de la lisis de las células puede ocurrir como resultado del incremento en la presión durante la filtración (Discart et al. 2015).

\section{PET y variables ambientales y biológicas}

El Sistema de la Corriente de California frente a Baja California se considera altamente dinámico en términos de fluctuaciones estacionales y espaciales de la producción primaria (Hernández de La Torre et al. 2004, Kahru et al. 2009, Gaxiola-Castro et al. 2010, Martínez-Gaxiola et al. 2010). Parte de esta variabilidad se origina de gradientes ambientales entre la costa y el océano abierto, y también a lo largo de procesos de mesoescala (Santamaria-del-Angel et al. 2002, Barocio-León et al. 2007). Al comienzo de esta investigación, se propuso describir la concentración de PET para dilucidar cómo esta es influenciada temporalmente y espacialmente por las propiedades ambientales y la producción primaria frente al norte de Baja California. En esta área, la incidencia de eventos intensos de surgencia promueve un aumento en la concentración de nutrientes inorgánicos en las capas superficiales y subsuperficiales de abril a junio (Pérez-Brunius et al. 2007, Durazo 2015) que estimula el crecimiento y la acumulación de biomasa de macroalgas y fitoplancton (Martínez-Gaxiola et al. 2010, Cruz-Trejo et al. 2015). Durante el periodo de estudio la surgencia más intensa fue en abril, tal como lo indican la disminución de profundidad de la capa de mezcla y la termoclina, y el enfriamiento de la capa superficial en las estaciones más cercanas a la costa. Las evidencias biológicas de los procesos de surgencia también se observaron mediante la dinámica de la Chla y la disminución de la profundidad del MPC en las estaciones más cercanas a la costa (Millán-Nuñez et al. 1997). Este comportamiento concuerda con algunas observaciones por satélite de la temperatura de la superficie del mar y del color del océano, así como con los índices de surgencia (e.g., Espinosa-Carreón et al. 2004, Gómez-Ocampo et al. 2017).

Nuestros datos mostraron concentraciones PET $>0.45 \mu \mathrm{m}$ relativamente altas $\left(>0.3 \mu \mathrm{g} \mathrm{XG} \mathrm{eq} \cdot \mathrm{mL}^{-1}\right)$, incluso en capas más profundas, en comparación con otras concentraciones publicadas para el mar abierto y para ambientes costeros y estuarinos (Wetz et al. 2009, Malpezzi et al. 2013, Annane et al. 2015, Benavides et al. 2015). La mayoría de los estudios de campo han mostrado incrementos en las concentraciones de PET durante o inmediatamente después de la madurez de las proliferaciones fitoplanctónicas (Passow 2002, Thornton 2002, Wetz et al. 2009). La dinámica temporal de las PET en el área de estudio siguió la tendencia estacional de la productividad primaria, la cual consiste en un aumento 
concentrations of TEP during phytoplankton blooms or immediately after phytoplankton bloom maturity (Passow 2002, Thornton 2002, Wetz et al. 2009). The temporal dynamics of TEP in the study area followed the seasonal trend of primary productivity, which consists in a significant increase toward spring that continues on with relatively high concentrations until early summer (Gaxiola-Castro et al. 2010). In February, the low phytoplankton biomass did not produce a substantial amount of TEP or TEP possibly degraded rapidly. In general, TEP decreased from the coast to the more offshore stations following the pattern reported by comparative studies for similar locations (influenced by upwelling) and other environmental gradients such as salinity (e.g., estuaries) and/or pollution (e.g., infringed by sewage, factories, or agricultural activities) (Chateauvert et al. 2012, Bar-Zeev and Rahav 2015). High concentrations of TEP close to the coast could also be strongly influenced by contributions from benthic invertebrates and macroalgae (Thornton 2004, McKee et al. 2005). This coastal increase in TEP is consistent with the distribution and the gross chemical composition of some macroalgae species from the Baja California Peninsula, which have been reported to contain more than $40 \%$ of carbohydrates (dry weight) in biomass (Serviere-Zaragoza et al. 2002, Hernández-Carmona et al. 2009). Thus, reserve and structural polysaccharides could be released to the environment as potential precursors of TEP after exudation or tissue rupture.

Relatively large TEP concentrations in deeper waters could be partly due to the seasonal increase in primary production levels, and these large concentrations are perhaps amplified by the attachment of ballast minerals that strengthen the vertical flux of particles (Ploug and Passow 2007, Iversen and Ploug 2010) and/or by spontaneous coagulation and breakdown of particulate organic matter in deeper layers (Engel et al. 2004, Wurl et al. 2011). A rough comparison between the depth-integrated carbon content of phytoplankton biomass estimated from Chla (assuming the $\mu \mathrm{g} \mathrm{C}$ to $\mu \mathrm{g} \mathrm{Chl} a$ ratio $=50$; Li et al. 2010), and the TEP carbon concentration for the first $100 \mathrm{~m}$ depth at all sampling stations, except the ENSENADA (up to $75 \mathrm{~m}$ depth) and MICMAR (up to 40 and $60 \mathrm{~m}$ depth in February and April, respectively) stations, suggests that the nonliving organic fraction on average contributes a $\sim 65$ fold (range: 2 to 264) larger amount to particulate carbon than phytoplankton cells do. Note that our estimations depend on the TEP-to-carbon conversion factors, which have a wide range of variation (from 0.51 to $0.88 \mu \mathrm{g} \mathrm{C} \cdot \mu \mathrm{g} \mathrm{XG} \mathrm{eq}{ }^{-1} \cdot \mathrm{mL}^{-1}$; Engel and Passow 2001). We currently lack a conversion factor for changing the concentration of alcian blue stained particles to particulate organic carbon for our region. Our results suggest that TEP could be responsible for up to $\sim 50 \%$ of the particulate organic carbon fluxes to the mesopelagic zone, as it has been described for other regions (Martin et al. 2011). In this study, TEP also exhibited relatively high concentra-

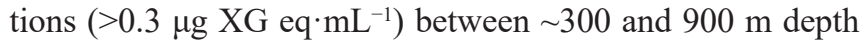
in June and April. The cause for these high concentrations is significativo hacia la primavera que se mantiene relativamente alto hasta principios de verano (Gaxiola-Castro et al. 2010). En febrero, la baja biomasa fitoplanctónica no produjo una cantidad sustancial de PET, o posiblemente las PET se degradaron rápidamente. En general, las PET disminuyeron de la costa a las estaciones más oceánicas siguiendo el patrón reportado por estudios comparativos para lugares similares (influenciados por la surgencia) y para otros gradientes ambientales tales como la salinidad (e.g., estuarios) y/o la contaminación (e.g., generada por aguas residuales, fábricas o actividades agrícolas) (Chateauvert et al. 2012, Bar-Zeev y Rahav 2015). Las altas concentraciones de PET cerca de la costa también podrían estar fuertemente influenciadas por las contribuciones de invertebrados bentónicos y macroalgas (Thornton 2004, McKee et al. 2005). Este incremento costero en las PET es consistente con la distribución y la composición química bruta de algunas especies de macroalgas de la península de Baja California, que según los reportes, contienen más del $40 \%$ de carbohidratos (peso seco) en su biomasa (Serviere-Zaragoza et al. 2002, Hernández-Carmona et al. 2009). De esta manera, los polisacáridos de reserva y estructurales podrían ser liberados al medioambiente como precursores potenciales de las PET después de la exudación o ruptura de tejido.

La concentración de PET relativamente alta en aguas más profundas podría deberse, en parte, a un aumento estacional en los niveles de producción primaria, y estas concentraciones quizás aumenten aún más por un efecto de adhesión a minerales que fortalecen el flujo vertical de partículas (Ploug y Passow 2007, Iversen y Ploug 2010), y/o por la coagulación espontánea y fragmentación de materia orgánica particulada en capas más profundas (Engel et al. 2004, Wurl et al. 2011). Una comparación aproximada entre el contenido de carbono integrado de la biomasa de fitoplancton estimada mediante Chl $a$ (suponiendo un cociente $\mu \mathrm{g} \mathrm{C}$ a $\mu \mathrm{g}$ Chl $a=50$; Li et al. 2010), y la concentración integrada de carbono asociada a las PET para los primeros $100 \mathrm{~m}$ de profundidad en todas las estaciones de muestreo, excepto la estación ENSENADA (hasta $75 \mathrm{~m}$ de profundidad) y la estación MICMAR (hasta $40 \mathrm{~m}$ y $60 \mathrm{~m}$ de profundidad en febrero y abril, respectivamente), sugiere que la fracción orgánica inerte contribuye en promedio una cantidad de carbono particulado $\sim 65$ veces (intervalo: 2 a 264) mayor que la que contribuyen las células del fitoplancton. Se debe considerar que nuestras estimaciones dependen de los factores de conversión existentes de las PET a carbono, los cuales tienen un rango de variación amplio (0.51 a $0.88 \mu \mathrm{g} \mathrm{C} \cdot \mu \mathrm{g} \mathrm{XG} \mathrm{eq}{ }^{-1} \cdot \mathrm{mL}^{-1}$; Engel y Passow 2001$)$. Actualmente, nosotros carecemos de un factor de conversión para cambiar de la concentración de partículas teñidas con azul alcián a carbono orgánico particulado para nuestra región. Nuestros resultados sugieren que las PET podrían ser responsables, como se ha descrito para otras regiones, de hasta el $50 \%$ de los flujos de carbono de partículas orgánicas a la zona mesopelágica (Martin et al. 2011). En este estudio, las PET también exhiben concentraciones relativamente altas 
not entirely clear, but it has been suggested that new organic precursors derived from physically and biologically mediated disintegration (e.g., sloppy feeding, viral lysis, swimming behavior of macrozooplankton) of settling fecal pellets and marine snow could later self-assemble as TEP in deep layers (Baldi et al. 1997; Prieto et al. 2001; Goldthwait et al. 2004, 2005). Some experimental assays in batch cultures indicate that there may be considerable differences in the origin and composition of TEP between upper and deeper layers. This is based on the fact that TEP in the oceanic euphotic zone proceed predominantly from exudates of photoautotrophic organisms, whereas in the deep layers they are heterotrophically produced through transformations by prokaryotes that increase their stickiness and recalcitrant properties (Barrera-Alba et al. 2008, Rochelle-Newall et al. 2010).

Regarding the ecological role of TEP, a weak but significant positive correlation between bacterioplankton abundances and TEP concentrations (Pearson's $R^{2}=0.38$, $P<0.05$; Fig. 6a) suggests a functional relationship, for example, in the releasing, aggregation, and recycling of organic matter, especially during events of high primary production (Ortega-Retuerta et al. 2010). Moreover, we estimated a statistically significant positive relationship between bacterioplankton abundance and TOC, as well as estimating a negative correlation between TEP and microbial respiration rates for the ANTARES station (Pearson's $R^{2}=0.61$ and 0.59 , respectively, $P<0.05$; Fig. $6 \mathrm{~b}, \mathrm{c}$ ). In the surface layer, these observed respiration rates corresponded to intermediate values compared to some estimates from oceanic areas (average: $2.4 \mu \mathrm{M} \mathrm{O}_{2} \cdot \mathrm{d}^{-1}$; range: $<0.7-12.7$; $n=51$ ) and upwelling zones (average: $6.5 \mu \mathrm{M} \mathrm{O}_{2} \cdot \mathrm{d}^{-1}$; range: undetectable to $33.4 ; n=132$; Robinson et al. 2002). However, below $100 \mathrm{~m}$ depth respiration rates were much greater than those detected in samples from the oxygen minimum zone (at $110 \mathrm{~m}$ depth, below the oxycline) in the tropical Pacific off western Mexico that were incubated under different dissolved oxygen levels (Tiano et al. 2014). Similarly, in this stratum and even deeper, TOC data fell in the range of large concentrations according to some database from the eastern North Pacific (Wheeler 2013). These relationships are consistent with the argument that microgels may be too large and their components very inaccessible or refractory to be consumed by prokaryotes (Verdugo 2012, Orellana and Leck 2015). In this study, the range of bacterial abundance was similar to the ranges reported for the surface layer in the southern California Current ecosystem (Linacre-Rojas et al. 2012, Samo et al. 2012); therefore, our evidence suggests that the conformation of organic matter during the study period seemed to serve as a physical substrate for settlement of microbial assemblages. This association could provide refuge against from nanoflagellate grazing and viral lysis rather than a supply of semi-labile carbon along the water column (Mari and Rassoulzadegan 2004, Mari et al. 2007, Weinbauer et al. 2009, Bar-Zeev et al. 2012). $\left(>0.3 \mu \mathrm{g} \mathrm{XG} \mathrm{eq} \cdot \mathrm{mL}^{-1}\right)$ entre los 300 y $900 \mathrm{~m}$ de profundidad en junio y abril. La causa de esta alta concentración no es del todo clara, pero se ha sugerido que los nuevos precursores orgánicos derivados de la desintegración de pelotillas fecales y nieve marina por agentes físicos y biológicos (e.g., babeo alimenticio, lisis viral, natación del macrozooplancton) podrían autoensamblarse más tarde como PET en capas profundas (Baldi et al. 1997; Prieto et al. 2001; Goldthwait et al. 2004, 2005). Algunos ensayos experimentales de cultivos discontinuos sugieren que pueden haber diferencias considerables en el origen y la composición de las PET entre capas superiores y más profundas. Esto se basa en el hecho de que las PET de la zona eufótica oceánica proceden predominantemente de exudados de organismos fotoautotróficos, mientras que en las capas profundas las PET se producen heterotróficamente a través de transformaciones por procariotas que aumentan su pegajosidad y propiedades recalcitrantes (Barrera-Alba et al. 2008, Rochelle-Newall et al. 2010).

En cuanto al papel ecológico de las PET, una correlación positiva débil pero significativa entre la abundancia de bacterioplancton y la concentración de PET $\left(R^{2}\right.$ de Pearson $=$ $0.38, P<0.05$; Fig. 6a) sugiere una asociación funcional, por ejemplo, en los procesos de liberación, agregación y reciclaje de materia orgánica, especialmente durante los eventos de alta producción primaria (Ortega-Retuerta et al. 2010). Por otra parte, la abundancia de bacterioplancton y COT presentó una relación positiva estadísticamente significativa, así como una correlación negativa entre las PET y las tasas de respiración microbiana en la estación ANTARES $\left(R^{2}\right.$ de Pearson $=0.61 \mathrm{y}$ 0.59 , respectivamente, $P<0.05$; Fig. $6 \mathrm{~b}, \mathrm{c})$. En la capa superficial, estas tasas de respiración corresponden a valores intermedios en comparación con algunas estimaciones de áreas oceánicas (promedio: $2.4 \mu \mathrm{M} \mathrm{O}_{2} \cdot \mathrm{d}^{-1}$; intervalo: $<0.7-12.7$; $n=51$ ) y zonas de surgencia (promedio: $6.5 \mu \mathrm{M} \mathrm{O}_{2} \cdot \mathrm{d}^{-1}$; intervalo: indetectable a 33.4; $n=132$; Robinson et al. 2002). Sin embargo, por debajo de $100 \mathrm{~m}$ de profundidad, nuestras tasas de respiración fueron mucho mayores que las detectadas en las muestras de la zona del mínimo de oxígeno (por debajo de la oxiclina a $110 \mathrm{~m}$ de profundidad) del Pacífico tropical frente a la costa occidental de México que fueron incubadas bajo diferentes niveles de oxígeno disuelto (Tiano et al. 2014). De manera similar, en estos estratos y en estratos más profundos, los datos de COT cayeron en el intervalo de concentraciones altas de acuerdo con la base de datos del Pacífico nororiental (Wheeler 2013). Estas relaciones son consistentes con el argumento de que los microgeles podrían ser demasiado grandes y sus componentes muy inaccesibles o refractarios para ser consumidos por procariotas (Verdugo 2012, Orellana y Leck 2015). En este estudio, el intervalo de abundancia bacteriana fue similar a los intervalos reportados para la capa superficial de la zona sureña del ecosistema de la corriente de California (Linacre-Rojas et al. 2012, Samo et al. 2012); por tanto, nuestras evidencias sugieren que esta conformación de materia orgánica durante el periodo de estudio parece servir más como un sustrato físico para el asentamiento de 

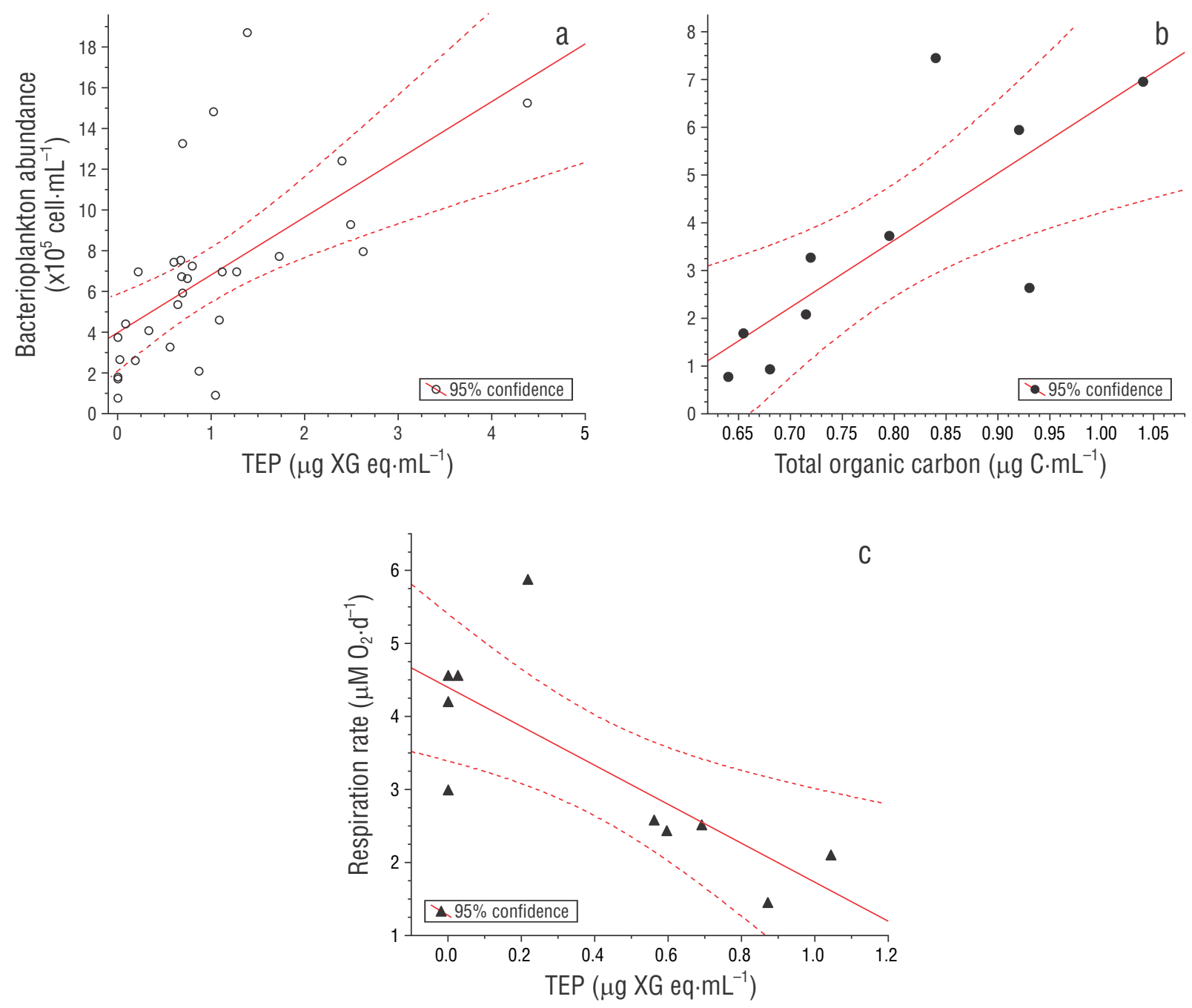

Figure 6. Scatter plots of bacterioplankton abundance $v s$ transparent exopolymer particles (TEP) (a), bacterioplankton abundance $v s$ total organic carbon $(\mathbf{b})$, and microbial respiration rate $v s \mathrm{TEP}(\mathbf{c})$. Linear regressions are as follows. (a) bacterioplankton abundance $\left(\times 105 \mathrm{cell} \cdot \mathrm{mL}^{-1}\right)=$ $2.83 \times\left(\mu \mathrm{g} \mathrm{XG} \mathrm{eq} \cdot \mathrm{mL}^{-1}\right)+3.98 ; R^{2}=0.38, n=30, P<0.05$. (b) Bacterioplankton abundance $\left(\times 105 \mathrm{cells} \cdot \mathrm{mL}^{-1}\right)=14.05 \times\left(\mu \mathrm{g} \mathrm{C} \cdot \mathrm{mL}^{-1}\right)-7.61 ; R^{2}$ $=0.61, n=10, P<0.05$. (c) Respiration rate $\left(\mu \mathrm{M} \mathrm{O}_{2} \cdot \mathrm{d}^{-1}\right)=-2.6682 \times\left(\mu \mathrm{g} \mathrm{XG} \mathrm{eq} \cdot \mathrm{mL}^{-1}\right)+4.3982 ; R^{2}=0.59, n=10, P<0.05$.

Figura 6. Diagramas de dispersión de la abundancia de bacterioplancton frente a las partículas transparentes de exopolímeros (TEP) (a), abundancia de bacterioplancton frente a carbono orgánico total (b) y tasa de respiración microbiana frente a TEP (c). Las regre-

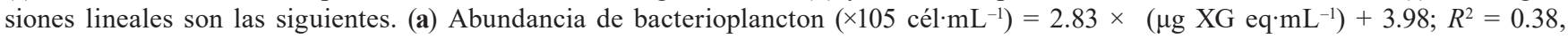
$n=30, P<0.05$. (b) Abundancia de bacterioplancton $\left(\times 105\right.$ cél $\left.\cdot \mathrm{mL}^{-1}\right)=14.05 \times\left(\mu \mathrm{g} \mathrm{C} \cdot \mathrm{mL}^{-1}\right)-7.61 ; R^{2}=0.61, n=10, P<0.05$. (c) Tasa de

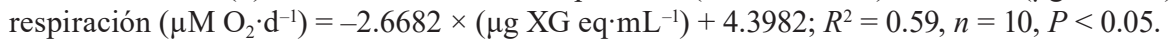

We are aware that the TEP magnitudes observed during the study period may have been affected by interannual variability or other low-frequency events (Kim and Miller 2006). The year 2016 was relatively warm due the prevalence of El Niño conditions during the first 6 months (NOAA-ERSL 2016). In the California Current System, the presence of El Niño has been associated with the deepening of the nutricline and possibly with a lower input of nutrients to the upper layer (Mann and Lazier 2006, Gómez-Ocampo et al. 2017). A depth-integrated primary production data set from 2003 to 2004 showed lower production values during a weak 20022003 El Niño in the winter time (Martínez-Gaxiola et al. ensamblajes microbianos. Esta asociación podría proporcionar un refugio contra el pastoreo por nanoflagelados y la lisis viral, en lugar de un suministro de carbono semi-lábil a lo largo de la columna de agua (Mari y Rassoulzadegan 2004, Mari et al. 2007, Weinbauer et al. 2009, Bar-Zeev et al. 2012).

Estamos conscientes de que las magnitudes de las PET observadas durante el periodo de estudio pudieron haber sido afectadas por la variabilidad interanual u otros eventos de baja frecuencia (Kim y Miller 2006). El año 2016 fue relativamente cálido debido a la prevalencia de condiciones de El Niño durante los primeros 6 meses (NOAA-ERSL 2016). En el Sistema de la Corriente de California, la presencia de 
2010). This low production is consistent with the progressive decrease of chlorophyll biomass during the 2015-2016 El Niño, as determined from satellite oceanic data and the Regional Ocean Modeling System (ROMS). However, this decrease is not as marked as the observed magnitudes of El Niño 3.4 Index suggest (Jacox et al. 2016). Our high concentrations of TEP could be comparable with those observed in some experimental studies, where under nutrient-limited conditions, growing phytoplankton cells are more likely to exude large amounts of polysaccharides (as TEP precursors) in the stationary phase (Guerrini et al. 1998, Wurl et al. 2011). Given the anomalously warm conditions, a positive effect on TEP aggregation would also be expected due to the increase in temperature to up to $32{ }^{\circ} \mathrm{C}$ (at $8.2 \mathrm{pH}$ ), which is the upper threshold experimentally established for the inhibition of marine microgel self-assembly (Seebah et al. 2014, Chen et al. 2015).

Our results indicate that the seasonal and spatial distribution of TEP is influenced by hydrographic properties and the dynamics of primary producers in the upper layer of the water column in the study area, which is part of the California Current System. In spring and early summer, dissolved organic precursors derived mainly from macroalgae and phytoplanktonic exudates and grazing (sloppy feeding, excretion, and defecation) are largely produced and spontaneously self-assembled as TEP in the euphotic zone. Thus, TEP associated to a ballast particle may be efficiently exported to the deep ocean, where their labile carbon is continuously subjected to consumption and heterotrophically transformed into refractory organic carbon. In a spatial scale, TEP tend to decrease predominantly along a trophic gradient from the most influenced upwelling location to offshore or oceanic waters. Hence, the present study corroborates that under relatively mesotrophic-to-eutrophic conditions, TEP seem to be more dependent on nutrient availability and photoautotrophic activity in the uppermost layers, whereas in the deeper layers TEP and their precursors are relatively more controlled by heterotrophically mediated processes that contribute to the increase of their degree of assemblage and recalcitrance (Lechtenfeld et al. 2015, Moran et al. 2016). Our carbon estimates based on depth-integrated TEP are strongly influenced by the conversion factor we chose and the pore size of the filter we used. This influence limits some interpretations regarding the contribution of TEP to the carbon budget, whereby the observed magnitudes can be considered mainly for relative spatiotemporal comparisons until a calibration of the method for this region has been performed. This potential contribution of carbon associated with TEP below the euphotic zone is more relevant in offshore waters than in nearshore areas, and it should be taken into account in future carbon budgets calling for better measurement methods. However, our relatively limited data set suggest that bacterioplankton is tightly coupled with TEP, serving mostly as a physical substrate rather than a labile or semi-labile carbon source. We recommend a more
El Niño se ha asociado con una profundización de la nutriclina y, probablemente, con un aporte menor de nutrientes a la capa superficial (Mann y Lazier 2006, Gómez-Ocampo et al. 2017). Una serie temporal de valores de producción primaria integrada desde 2003 hasta 2004 mostró valores más bajos en el invierno de 2002-2003 durante un evento de El Niño débil (Martínez-Gaxiola et al. 2010). Esta baja producción es consistente con la disminución progresiva de la biomasa de la clorofila durante el periodo de El Niño de 2015-2016, que se determinó mediante observaciones de datos oceánicos satelitales y la aplicación del Sistema Regional de Modelización Oceánica (ROMS, por sus siglas en ingles). No obstante, esta disminución no fue tan acentuada como sugiere la magnitud observada del índice de El Niño 3.4 (Jacox et al. 2016). Nuestras altas concentraciones de PET podrían ser comparables con las observadas en algunos estudios experimentales, donde bajo condiciones limitantes por nutrientes, las células de fitoplancton en crecimiento son más propensas a exudar grandes cantidades de polisacáridos (como precursores de PET) en fase estacionaria (Guerrini et al. 1998, Wurl et al. 2011). Aunado a una condición climática anormalmente cálida, también podría esperarse un efecto positivo en la agregación de las PET por el aumento de la temperatura hasta $32{ }^{\circ} \mathrm{C}$ (a $8.2 \mathrm{de} \mathrm{pH}$ ), que es el umbral superior establecido experimentalmente para la inhibición del autoensamblaje de microgeles marinos (Seebah et al. 2014, Chen et al. 2015).

Nuestros resultados indican que la distribución estacional y espacial de las PET está influenciada por las propiedades hidrográficas y la dinámica de los productores primarios en la capa superficial del área de estudio que se encuentra dentro del Sistema de la Corriente de California. En la primavera y principios del verano, los precursores orgánicos disueltos derivados principalmente de exudados de macroalgas y fitoplancton y del pastoreo (babeo alimenticio, excreción y defecación) se producen en gran medida y se autoensamblan espontáneamente como PET en la zona eufótica. De esta manera, las PET asociadas a una partícula de lastre pueden ser exportadas eficientemente al océano profundo, donde su carbono lábil continuamente está sujeto al consumo y es transformado heterotróficamente a carbono orgánico refractario. En la escala espacial, las PET tienden a disminuir predominantemente a lo largo de un gradiente trófico desde la zona más influenciada por eventos de surgencia hasta las aguas mar adentro u oceánicas. Por lo tanto, el presente estudio corrobora que en condiciones relativamente mesotróficas y eutróficas, las PET parecen ser más dependientes de la disponibilidad de nutrientes y la actividad fotoautotrófica en las capas más superficiales, mientras que en las capas más profundas estas y sus precursores son relativamente más controlados por procesos modulados heterotróficamente que contribuyen al incremento de su grado de ensamblaje y propiedades recalcitrantes (Lechtenfeld et al. 2015, Moran et al. 2016). Nuestras estimaciones de carbono basadas en valores integrados de las PET están fuertemente influenciadas por el factor de conversión elegido y el tamaño de poro del filtro utilizado. 
intense time series monitoring of TEP to corroborate their seasonal trends and magnitudes in years influenced by various oceanographic processes at interannual and decadal scales, together with the differences in the concentrations of alcian blue stainable particles collected with different filter pore sizes. Future studies must also assess the physiological implications of TEP on prokaryotic activity and their significance in the organic carbon budget.

\section{ACKNOWLEDGMenTS}

The authors gratefully acknowledge financial support obtained from the project SEP-CONACYT CB-201201/179753 and the Universidad Autónoma de Baja California. Thanks go to the Secretariat of Public Education (SEP, Mexico) for the postdoctoral scholarship (PROMEP) granted to CHS. Special thanks go to the Marine Microbial Laboratory at CICESE for offering its facilities and logistical support and equipment. We thank also the staff from the Laboratory of CeMIEGeo at CICESE for their assistance in conducting the TOC tests.

\section{REFERENCES}

Alldredge AL, Passow U, Logan BE. 1993. The abundance and significance of a class of large, transparent organic particles in the ocean. Deep-Sea Res. (I Oceanogr. Res. Pap.) 40 (6): 11311140 .

Annane S, St-Amand L, Starr M, Pelletier E, Ferreyra GA. 2015. Contribution of transparent exopolymeric particles (TEP) to estuarine particulate organic carbon pool. Mar. Ecol. Prog. Ser. 529: 17-34.

https://doi.org/10.3354/meps11294

Azetsu-Scott K, Niven SEH. 2005. The role of transparent exopolymer particles (TEP) in the transport of Th-234 in coastal water during a spring bloom. Cont. Shelf Res. 25(9): 1133-1141. https://doi.org/10.1016/j.csr.2004.12.013

Baldi F, Minacci A, Saliot A, Mejanelle L, Mozetic P, Turk V, Malej A. 1997. Cell lysis and release of particulate polysaccharides in extensive marine mucilage assessed by lipid biomarkers and molecular probes. Mar. Ecol. Prog. Ser. 153: 45-57. https://doi.org/10.3354/meps153045

Baltar F, Currie K, Meyer M, Verdugo P. 2016. Proportion of marine organic carbon present in self-assembled gels along the subtropical front and its increase in response to reduced $\mathrm{pH}$. Mar. Chem. 184: 53-59. https://doi.org/10.1016/j.marchem.2016.05.014

Barocio-León OA, Millán-Núñez R, Santamaría-del-Ángel E, González-Silvera A. 2007. Productividad primaria del fitoplancton en la zona eufótica del Sistema de la Corriente de California estimada mediante imágenes del $\mathrm{CZCS}=$ Phytoplankton primary productivity in the euphotic zone of the California Current System estimated from CZCS imagery. Cienc. Mar. 33(1): 59-72. http://dx.doi.org/10.7773/cm.v33i1.1037

Barrera-Alba JJ, Gianesella SMF, Moser GAO, Saldanha-Corrêa FMP. 2008. Bacterial and phytoplankton dynamics in a subtropical estuary. Hydrobiologia 598(1): 229-246. https://doi.org/10.1007/s10750-007-9156-4

Bar-Zeev E, Berman-Frank I, Girshevitz O, Berman T. 2012. Revised paradigm of aquatic biofilm formation facilitated by microgel transparent exopolymer particles. Proc. Natl. Acad.
Esto limita algunas de las interpretaciones con respecto a la contribución de las PET al presupuesto de carbono; por tanto, las magnitudes observadas podrían considerarse principalmente para comparaciones espaciotemporales relativas hasta que se realice una calibración del método para esta región. Esta contribución potencial del carbono asociado a las PET por debajo de la zona eufótica adquiere mayor relevancia en las aguas mar adentro que en las estaciones costeras, lo cual es una característica notable a considerar para los futuros presupuestos de carbono que requieren mejores métodos de medición. Sin embargo, nuestro conjunto de datos relativamente limitado sugiere que el bacterioplancton está estrechamente acoplado con las PET, las cuales sirven principalmente como un sustrato físico en lugar de una fuente de carbono lábil o semi-lábil. Se recomienda un monitoreo más intenso de las PET para corroborar sus tendencias y magnitudes estacionales en años influenciados por diversos procesos oceanográficos en la escala interanual y la decadal, junto con las diferencias de las concentraciones de partículas teñidas con azul alcián retenidas con filtros con diferentes tamaños de poro. Además, los estudios futuros deben evaluar las implicaciones fisiológicas de las PET sobre la actividad procariótica, así como su relevancia en el presupuesto de carbono orgánico.

\section{Agradecimientos}

Los autores agradecen el apoyo financiero del proyecto SEP-CONACYT CB-2012-01/179753 y de la Universidad Autónoma de Baja California. Gracias a la Secretaría de Educación Pública (SEP) a través de PROMEP por la beca postdoctoral otorgada a CHS. Un agradecimiento especial al Laboratorio de Microbiología Marina de CICESE por ofrecer sus instalaciones, apoyo logístico y equipamiento. Agradecemos también al personal del Laboratorio de CeMIEGeo de CICESE por su asistencia en la realización de las pruebas del COT.

Sci. USA. 109(23): 9119-9124.

https://doi.org/10.1073/pnas.1203708109

Bar-Zeev E, Rahav E. 2015. Microbial metabolism of transparent exopolymer particles during the summer months along a eutrophic estuary system. Front. Microbiol. 6: 403. https://doi.org/10.3389/fmicb.2015.00403

Benavides M, Moisander PH, Berthelot H, Dittmar T, Grosso O, Bonnet S. 2015. Mesopelagic $\mathrm{N}_{2}$ Fixation Related to Organic Matter Composition in the Solomon and Bismarck Seas (Southwest Pacific). PLoS ONE 10(12): e0143775. https://doi.org/10.1371/journal.pone.0143775

Berggren M, Lapierre JF, del Giorgio PA. 2012. Magnitude and regulation of bacterioplankton respiratory quotient across freshwater environmental gradients. ISME J. 6(5): 984-993. https://doi.org/10.1038/ismej.2011.157

Bochdansky AB, Clouse MA, Hernd GJ. 2016. Dragon kings of the deep sea: marine particles deviate markedly from the common 
number-size spectrum. Sci. Rep. 6(1): 22633.

https://doi.org/10.1038/srep22633

Chateauvert CA, Lesack LFW, Bothwell ML. 2012. Abundance and patterns of transparent exopolymer particles (TEP) in arctic floodplain lakes of the Mackenzie River Delta. J. Geophys. Res. 117(G4): G04013. https://doi.org/10.1029/2012jg002132

Chen CS, Anaya JM, Chen EYT, Farr E, Chin WC. 2015. Ocean warming-acidification synergism undermines dissolved organic matter assembly. PLoS ONE 10(2): e0118300. https://doi.org/10.1371/journal.pone.0118300

Chen J, Thornton DCO. 2015. Transparent exopolymer particle production and aggregation by a marine planktonic diatom (Thalassiosira weissflogii) at different growth rates. J. phycol. 51(2): 381-393.

https://doi.org/10.1111/jpy.12285

Chin WC, Orellana MV, Verdugo P. 1998. Spontaneous assembly of marine dissolved organic matter in polymer gels. Nature 391: $568-572$

Cruz-Trejo GI, Ibarra-Obando SE, Aguilar-Rosas LE, PoumianTapia M, Solana-Arellano ME. 2015. Presence of Sargassum horneri at Todos Santos Bay, Baja California, Mexico: its effects on the local macroalgae community. Am. J. Plant Sci. 6: 26932707.

http://dx.doi.org/10.436/ajps.2015.617271

Ding YX, Hung CC, Santschi PH, Verdugo P, Chin WC. 2009. Spontaneous assembly of exopolymers from phytoplankton. TAO 20(5): 741-747. https://doi.org/10.3319/tao.2008.08.26.01(oc)

Discart V, Bilad MR, Vankelecom IFJ. 2015. Critical evaluation of the determination methods for transparent exopolymer particles (TEP), agents of membrane fouling. Crit. Rev. Environ. Sci. Technol. 45(2): 167-192.

https://doi.org/10.1080/10643389.2013.829982

Durazo R. 2015. Seasonality of the transitional region of the California Current System off Baja California. J. Geophys. Res. (Oceans) 120(2): 1173-1196. https://doi.org/10.1002/2014jc010405

Engel A. 2000. The role of transparent exopolymer particles (TEP) in the increase in apparent particle stickiness $(\alpha)$ during the decline of a diatom bloom. J. Plankton Res. 22(3): 485-497. https://doi.org/10.1093/plankt/22.3.485

Engel A. 2004. Distribution of transparent exopolymer particles (TEP) in the northeast Atlantic Ocean and their potential significance for aggregation processes. Deep-Sea Res. (I Oceanogr. Res. Pap.) 51(1): 83-92. https://doi.org/10.1016/j.dsr.2003.09.001

Engel A, Passow U. 2001.Carbon and nitrogen content of transparent exopolymer particles (TEP) in relation to their Alcian Blue adsorption. Mar. Ecol. Prog. Ser. 219: 1-10. https://doi.org/10.3354/meps219001

Engel A, Thoms S, Riebesell U, Rochelle-Newall E, Zondervan I. 2004. Polysaccharide aggregation as a potential sink of marine dissolved organic carbon. Nature 428(6986): 929-932. https://doi.org/10.1038/nature02453

Espinosa-Carreón TL, Strub PT, Beier E, Ocampo-Torres F, Gaxiola-Castro G. 2004. Seasonal and interannual variability of satellite-derived chlorophyll pigment, surface height, and temperature off Baja California. J. Geophys. Res. (C Oceans) 109(C3): C03039. https://doi.org/10.1029/2003jc002105

Gaxiola-Castro G, Cepeda-Morales JCA, Najera-Martínez S, Espinosa-Carreón TL, De la Cruz-Orozco ME, Sosa-Avalos R, Aguirre-Hernández E, Cantú-Ontiveros JP. 2010. Biomasa y producción de fitoplancton. In: Gaxiola-Castro
G, Durazo R (eds.), Dinámica del ecosistema pelágico frente a Baja California, 1997-2007: Diez años de investigaciones mexicanas de la Corriente de California. Secretaría de Medio Ambiente y Recursos Naturales, Mexico City, pp. 59-86.

Goldthwait S, Yen J, Brown J, Alldredge AL. 2004. Quantification of marine snow fragmentation by swimming euphausiids. Limnol. Oceanogr. 49(4): 940-952. https://doi.org/10.4319/1o.2004.49.4.0940

Goldthwait SA, Carlson CA, Henderson GK, Alldredge AL. 2005. Effects of physical fragmentation on remineralization of marine snow. Mar. Ecol. Prog. Ser. 305: 59-65. https://doi.org/10.3354/meps305059

Gómez-Ocampo E, Gaxiola-Castroa G, Durazo R, Beier E. 2017. Effects of the 2013-2016 warm anomalies on the California Current phytoplankton. Deep-Sea Res. (II Top. Stud. Oceanogr.).

https://doi.org/10.1016/j.dsr2.2017.01.005

Guerrini F, Mazzoti A, Boni L, Pistocchi R. 1998. Bacterial-algal interactions in polysaccharide production. Aquat. Microb. Ecol. 15: 247-253. https://doi.org/10.3354/ame015247

Hernández-Carmona G, Carrillo-Domínguez S, Arvizu-Higuera DL, Rodríguez-Montesinos YE, Murillo-Álvarez JI, MuñozOchoa M, Castillo-Domínguez RM. 2009. Monthly variation in the chemical composition of Eisenia arborea J. E. Areschoug. J. App. Phycol. 21(5): 607-616. https://doi.org/10.1007/s10811-009-9454-5

Hernández de La Torre B, Gaxiola-Castro G, Nájera-Martínez S. 2004. ENSO effects on primary production off Baja California. Cienc. Mar. 30(3): 427-441. https://doi.org/10.7773/cm.v30i3.330

Iversen MH, Ploug H. 2010. Ballast minerals and the sinking carbon flux in the ocean: carbon-specific respiration rates and sinking velocity of marine snow aggregates. Biogeosciences 7(9): 26132624. https://doi.org/10.5194/bg-7-2613-2010

Jacox MG, Hazen EL, Zaba KD, Rudnick DL, Edwards CA, Moore AM, Bograd SJ. 2016. Impacts of the 2015-2016 El Niño on the California Current System: Early assessment and comparison to past events. Geophys. Res. Lett. 43(13): 7072-7080. https://doi.org/10.1002/2016g1069716

Jeronimo G, Gomez-Valdes J. 2010. Mixed layer depth variability in the tropical boundary of the California Current, 1997-2007. J. Geophys. Res. (C Oceans) 115(C5): C05014. https://doi.org/10.1029/2009jc005457

Kahru M, Kudela R, Manzano-Sarabia M, Mitchell BG. 2009. Trends in primary production in the California Current detected with satellite data. J. Geophys. Res. (C Oceans) 114(C2): C02004. https://doi.org/10.1029/2008jc004979

Kaltenböck E, Herndl GJ. 1992. Ecology of amorphous aggregations (marine snow) in the northern Adriatic Sea. IV. Dissolved nutrients and the autotrophic community associated with marine snow. Mar. Ecol. Prog. Ser. 87: 147-159. https://doi.org/10.3354/meps087147

Kara AB, Rochford PA, Hurlburt HE. 2000. An optimal definition for ocean mixed layer depth. J. Geophys. Res. (C Oceans) 105(C7): 16803-16821. https://doi.org/10.1029/2000jc900072

Kepner RL, Pratt JR. 1994. Use of fluorochromes for direct enumeration of total bacteria in environmental samples: past and present. Microbiol. Rev. 58(4): 603-6175.

Kim HJ, Miller AJ. 2007. Did the Thermocline Deepen in the California Current after the 1976/77 Climate Regime Shift? J. 
Phys. Oceanogr. 37(6): 1733-1739.

https://doi.org/10.1175/jpo3058.1

Koike I, Hara S, Terauchi K, Kogure K. 1990. Role of submicrometre particles in the ocean. Nature 345(6272): 242-244. https://doi.org/10.1038/345242a0

Lechtenfeld OJ, Hertkorn N, Shen Y, Witt M, Benner R. 2015. Marine sequestration of carbon in bacterial metabolites. Nat. Commun. 6: 6711. https://doi.org/10.1038/ncomms7711

Li QP, Franks PJS, Landry MR, Goericke R, Taylor AG. 2010. Modeling phytoplankton growth rates and chlorophyll to carbon ratios in California coastal and pelagic ecosystems. J. Geophys. Res. Biogeosci. 115:G04003. https://doi.org/10.1029/2009JG001111

Linacre L, Landry MR, Cajal-Medrano R, Lara-Lara JR, Hernández-Ayón JM, Mouriño-Pérez RR, García-Mendoza E, Bazán-Guzmán MC. 2012. Temporal dynamics of carbon flow through the microbial plankton community in a coastal upwelling system off northern Baja California, Mexico. Mar. Ecol. Prog. Ser. 461: 31-46. https://doi.org/10.3354/meps09782

Malpezzi MA, Sanfor, LP, Crump BC. 2013. Abundance and distribution of transparent exopolymer particles in the turbidity maximum of Chesapeake Bay. Mar. Ecol. Prog. Ser. 486: 23-35. https://doi.org/10.3354/meps10362

Mann KH, Lazier JRN. 2013. Vertical Structure of the Open Ocean: Biology of the Mixed Layer. Dynamics of Marine Ecosystems. Third ed. Oxford: Blackwell Publishing. 68-117. http://dx.doi.org/10.1002/9781118687901.ch3

Mari X, Kerros ME, Weinbauer MG. 2007. Virus attachment to transparent exopolymeric particles along trophic gradients in the southwestern lagoon of New Caledonia. Appl. Environ. Microb. 73(16): 5245-5252.

Mari X, Rassoulzadegan F. 2004. Role of TEP in the microbial food web structure. I. Grazing behavior of a bacterivorous pelagic ciliate. Mar. Ecol. Prog. Ser. 279: 13-22.

https://doi.org/10.3354/meps279013

Martin P, Lampitt RS, Perry MJ, Sanders R, Lee C, D'Asaro E. 2011. Export and mesopelagic particle flux during a North Atlantic spring diatom bloom. Deep-Sea Res. (I Oceanogr. Res. Pap.) 58(4): 338-349.

https://doi.org/10.1016/j.dsr.2011.01.006

Martínez-Gaxiola MD, Durazo R, Gaxiola-Castro G. 2010. Influence of the geostrophic transport of phosphates on primary production off Baja California (Mexico). Cienc. Mar. 36(2): 135-145. http://dx.doi.org/10.7773/cm.v36i2.1660

McKee MP, Ward JE, MacDonald BA, Holohan BA. 2005. Production of transparent exopolymer particles (TEP) by the eastern oyster Crassostrea virginica. Mar. Ecol. Prog. Ser. 288: 141-149.

https://doi.org/10.3354/meps288141

Millán-Núñez R, Álvarez-Borrego S, Trees CC. 1997. Modeling the vertical distribution of chlorophyll in the California Current System. J. Geophys. Res. (C Oceans) 102(C4): 8587-8595. https://doi.org/10.1029/97jc00079

Moran MA, Kujawinski EB, Stubbins A, Fatland R, Aluwihare LI, Buchan A, Crump BC, Dorrestein PC, Dyhrman ST, Hess NJ, Howe B, Longnecker K, Medeiros PM, Niggemann J, Obernosterer I, Repeta DJ, Waldbauer JR. 2016. Deciphering ocean carbon in a changing world. Proc. Natl. Acad. Sci. USA 113: 3143-3151.

[NOAA-ERSL] National Oceanic and Atmospheric Administration-Earth System Research Laboratory. 2016. Multivariate ENSO Index data archive [accessed February 2017]. https://www.esrl.noaa.gov/psd/enso/mei/.
Orellana MV, Leck C. 2015. Marine microgels. In: Hansell DA, Carlson CA (eds.), Biogeochemistry of marine dissolved organic matter. 2nd ed. Academic Press, Elsevier, London, pp. $451-480$.

Ortega-Retuerta E, Duarte CM, Reche I. 2010. Significance of bacterial activity for the distribution and dynamics of transparent exopolymer particles in the Mediterranean Sea. Microb. Ecol. 59(4): 808-818. https://doi.org/10.1007/s00248-010-9640-7

Passow U. 2002. Production of transparent exopolymer particles (TEP) by phyto- and bacterioplankton. Mar. Ecol. Prog. Ser. 236: $1-12$ https://doi.org/10.3354/meps236001

Passow U. Alldredge AL. 1995. A dye-binding assay for the spectrophotometric measurement of transparent exopolymer particles (TEP). Limnol. Oceanogr. 40(7): 1326-1335. https://doi.org/10.4319/1o.1995.40.7.1326

Pérez-Brunius P, López M, Pares-Sierra A, Pineda J. 2007. Comparison of upwelling indices off Baja California derived from three different wind data sources. CalCOFI Rep. 48: 204214.

Ploug H, Passow U. 2007. Direct measurement of diffusivity within diatom aggregates containing transparent exopolymer particles. Limnol. Oceanogr. 52(1): 1-6. https://doi.org/10.4319/10.2007.52.1.0001

Prieto L, Sommer F, Stibor H, Wolgang K. 2001. Effects of planktonic copepods on transparent exopolymeric particles (TEP) abundance and size spectra. J. Plankton Res. 23(5): 515525. https://doi.org/10.1093/plankt/23.5.515

Robinson C, Serret P, Tilstone G, Teira E, Zubkov MV, Rees AP, Woodward EMS. 2002. Plankton respiration in the Eastern Atlantic Ocean. Deep-Sea Res. (I Oceanogr. Res. Pap.) 49(5): 787-813. https://doi.org/10.1016/s0967-0637(01)00083-8

Rochelle-Newall EJ, Mari X, Pringault O. 2010. Sticking properties of transparent exopolymeric particles (TEP) during aging and biodegradation. J. Plankton Res. 32(10): 1433-1442. https://doi.org/10.1093/plankt/fbq060

Samo TJ, Pedler BE, Pasulka AL, Ball GI, Pasulka AL, Taylor AG, Aluwihare LI, Azam F, Goericke R, Landry MR. 2012. Microbial distribution and activity across a water mass frontal zone in the California Current. J. Plankton Res. 34(9): 802-814. https://doi.org/10.1093/plankt/fbs048

Santamaria-del-Angel E, Millan-Nuñez R, Gonzalez-Silvera A, Müller-Karger F. 2002. The color signature of the Ensenada Front and its seasonal and interannual variability. CalCOFI Rep. 43: 155-161.

Santschi PH, Balnois E, Wilkinson KJ, Zhang J, Buffle J, Guo L. 1998. Fibrillar polysaccharides in marine macromolecular organic matter as imaged by atomic force microscopy and transmission electron microscopy. Limnol. Oceanogr. 43(5): 896-908. https://doi.org/10.4319/10.1998.43.5.0896

Seebah S, Fairfield C, Ullrich MS, Passow U. 2014. Aggregation and sedimentation of Thalassiosira weissflogii (diatom) in a warmer and more acidified future ocean. PLoS ONE 9(11): e112379. https://doi.org/10.1371/journal.pone.0112379

Serviere-Zaragoza E, Gómez-López D, Ponce-Díaz G. 2002. Composición química gruesa de tres macroalgas y un pasto marino en la costa del Pacífico de Baja California, México. Hidrobiológica (Iztapalapa) 12(2): 113-118.

Stoderegger KE, Herndl GJ. 1999. Production of exopolymer particles by marine bacterioplankton under contrasting 
turbulence conditions. Mar. Ecol. Prog. Ser. 189: 9-16. https://doi.org/10.3354/meps189009

Sun CC, Wang YS, Li QP, Yue WZ, Wang YT, Sun FL, Peng YL. 2012. Distribution characteristics of transparent exopolymer particles in the Pearl River estuary, China. J. Geophys. Res. 117(G4): G00N17. https://doi.org/10.1029/2012jg001951

Surge DM, Lohmann KC. 2002. Temporal and spatial differences in salinity and water chemistry in SW Florida estuaries: effects of human-impacted watersheds. Estuaries 25(3): 393-408. https://doi.org/10.1007/bf02695982

Thornton DCO. 2002. Diatom aggregation in the sea: mechanisms and ecological implications. Eur. J. Phycol. 37(2): 149-161. https://doi.org/10.1017/s0967026202003657

Thornton DCO. 2004. Formation of transparent exopolymeric particles (TEP) from macroalgal detritus. Mar. Ecol. Prog. Ser. 282: $1-12$. https://doi.org/10.3354/meps282001

Tiano L, Garcia-Robledo E, Revsbech NP. 2014. A new highly sensitive method to assess respiration rates and kinetics of natural planktonic communities by use of the switchable trace oxygen sensor and reduced oxygen concentrations. PLoS ONE 9(8): e105399. https://doi.org/10.1371/journal.pone.0105399

Verdugo P. 2012. Marine microgels. Annu. Rev. Mar. Sci. 4: 375400. https://doi.org/10.1146/annurev-marine-120709-142759

Villacorte LO, Ekowati Y, Calix-Ponce HN, Schippersa JC, Amya GL, Kennedya MD. 2015. Improved method for measuring transparent exopolymer particles (TEP) and their precursors in fresh and saline water. Water Res. 70: 300-312. https://doi.org/10.1016/j.watres.2014.12.012

Villacorte LO, Kennedy MD, Amy GL, Schippers JC. 2009. The fate of transparent exopolymer particles (TEP) in integrated membrane systems: Removal through pre-treatment processes and deposition on reverse osmosis membranes. Water Res. 43(20): 5039-5052. https://doi.org/10.1016/j.watres.2009.08.030

Villegas-Mendoza JR, Cajal-Medrano R, Maske H. 2015. INT (2-(4-iodophenyl)-3-(4-nitrophenyl)-5-(phenyl) tetrazolium chloride) is toxic to prokaryote cells precluding its use with whole cells as a proxy for in vivo respiration. Microb. Ecol. 70(4):1004-1011. https://doi.org/10.1007/s00248-015-0626-3

Weinbauer MG, Bettarel Y, Cattaneo R, Luef B, Maier C, Motegi C, Peduzzi P, Mari X. 2009. Viral ecology of organic and inorganic particles in aquatic systems: avenues for further research. Aquat. Microb. Ecol. 57(3): 321-341. https://doi.org/10.3354/ame01363

Wells ML, Goldberg ED. 1991. Occurrence of small colloids in sea water. Nature 353(6342): 342-344. https://doi.org/10.1038/353342a0

Wetz MS, Robbins M, Paerl HW. 2009. Transparent exopolymer particles (TEP) in a river-dominated estuary: Spatial-temporal distributions and controls upon TEP formation. Estuar. Coast. 32(3): 447-455.

Wheeler P. 2013. Salinity, total nitrogen, water temperature, particulate organic carbon and other profile and discrete sample data collected in the North Pacific Ocean on the ATLANTIS, NEW HORIZON and WECOMA cruises AT7-21, NH0307A and others as part of the NEP project from 1997-09-19 to 2004-09-02 (NODC Accession 0115198). Version 1.1. National Oceanographic Data Center, NOAA. [Available online at https://data.nodc.noaa. gov/cgi-bin/iso?id=gov.noaa.nodc:0115198].

Wurl O, Miller L, Vagle S. 2011. Production and fate of transparent exopolymer particles in the ocean. J. Geophys. Res. (C Oceans) 116: $\mathrm{C} 00 \mathrm{H} 13$. https://doi.org/10.1029/2011jc007342

Received February 2017, Accepted August 2017. 